University of Nebraska - Lincoln

DigitalCommons@University of Nebraska - Lincoln

US Army Research

U.S. Department of Defense

2010

\title{
Activity of topical antimicrobial agents against multidrug-resistant bacteria recovered from burn patients
}

Jessie S. Glasser

San Antonio Military Medical Center

Charles H. Guymon

US Army Institute of Surgical Research

Katrin Mende

Infectious Disease Clinical Research Program

Steven E. Wolf

San Antonio Military Medical Center

Duane R. Hospenthal

University of Texas Health Science Center at San Antonio,

See next page for additional authors

Follow this and additional works at: https://digitalcommons.unl.edu/usarmyresearch

Part of the Operations Research, Systems Engineering and Industrial Engineering Commons

Glasser, Jessie S.; Guymon, Charles H.; Mende, Katrin; Wolf, Steven E.; Hospenthal, Duane R.; and Murray, Clinton K., "Activity of topical antimicrobial agents against multidrug-resistant bacteria recovered from burn patients" (2010). US Army Research. 126.

https://digitalcommons.unl.edu/usarmyresearch/126

This Article is brought to you for free and open access by the U.S. Department of Defense at DigitalCommons@University of Nebraska - Lincoln. It has been accepted for inclusion in US Army Research by an authorized administrator of DigitalCommons@University of Nebraska - Lincoln. 


\section{Authors}

Jessie S. Glasser, Charles H. Guymon, Katrin Mende, Steven E. Wolf, Duane R. Hospenthal, and Clinton K. Murray 


\title{
Activity of topical antimicrobial agents against multidrug-resistant bacteria recovered from burn patients ${ }^{\text {is }}$
}

\author{
Jessie S. Glasser ${ }^{a}$, Charles H. Guymon ${ }^{b}$, Katrin Mende ${ }^{a, c}$, Steven E. Wolf ${ }^{a, b, d}$, \\ Duane R. Hospenthal ${ }^{a, d, e}$, Clinton K. Murray ${ }^{a, d, e, *}$
}

a San Antonio Military Medical Center, Fort Sam Houston, TX, United States

${ }^{\mathrm{b}}$ US Army Institute of Surgical Research, Fort Sam Houston, TX, United States

${ }^{\mathrm{c}}$ Infectious Disease Clinical Research Program, Bethesda, MD, United States

${ }^{\mathrm{d}}$ University of Texas Health Science Center at San Antonio, San Antonio, TX, United States

${ }^{\mathrm{e}}$ Uniformed Services University of the Health Sciences, Bethesda, MD, United States

\section{A R T I C L E I N F O}

\section{Article history:}

Accepted 11 May 2010

Keywords:

Burn

Topical

\begin{abstract}
A B S T R A C T
Background: Topical antimicrobials are employed for prophylaxis and treatment of burn wound infections despite no established susceptibility breakpoints, which are becoming vital in an era of multidrug-resistant (MDR) bacteria. We compared two methods of determining topical antimicrobial susceptibilities.

Methods: Isolates of Pseudomonas aeruginosa, methicillin-resistant Staphylococcus aureus (MRSA), extended spectrum beta-lactamase (ESBL) producing Klebsiella pneumoniae, and Acinetobacter baumanii-calcoaceticus $(\mathrm{ABC})$ from burn patients were tested using broth microdilution and agar well diffusion to determine minimum inhibitory concentrations (MICs) and zones of inhibition (ZI). Isolates had systemic antibiotic resistance and clonality determined. MDR included resistance to antibiotics in three or more classes.

Results: We assessed 22 ESBL-producing K. pneumoniae, 20 ABC (75\% MDR), 20 P. aeruginosa (45\% MDR), and 20 MRSA isolates. The most active agents were mupirocin for MRSA and mafenide acetate for the gram-negatives with moderate MICs/ZI found with silver sulfadiazene, silver nitrate, and honey. MDR and non-MDR isolates had similar topical resistance. There was no clonality associated with resistance patterns.

Conclusion: Despite several methods to test bacteria for topical susceptibility, no defined breakpoints exist and standards need to be established. We recommend continuing to use silver products for prophylaxis against gram-negatives and mafenide acetate for treatment, and mupirocin for MRSA.
\end{abstract}

Published by Elsevier Ltd and ISBI

\section{Introduction}

Improvements in burn care have led to longer survival but have extended hospital stays. Patients who perish after surviving the initial burn insult and resuscitation are most likely to die from infectious complications [1]. Burn patients are relatively immunosuppressed and are at high risk of infections, in particular with nosocomially-acquired multi-

\footnotetext{
The opinions or assertions contained herein are the private views of the authors and are not to be construed as official or reflecting the views of the Department of the Army, Department of Defense, or the US government. This work was prepared as part of their official duties and, as such, there is no copyright to be transferred.

* Corresponding author at: Infectious Disease Service, San Antonio Military Medical Center, Brooke Army Medical Center, 3851 Roger Brooke Drive, Fort Sam Houston, TX 78234, United States. Tel.: +1 210916 8752; fax: +1 2109160388.

E-mail address: Clinton.Murray@amedd.army.mil (C.K. Murray). 0305-4179/\$36.00. Published by Elsevier Ltd and ISBI doi:10.1016/j.burns.2010.05.013
} 
drug-resistant (MDR) organisms [2]. Burns result in loss of the first line of immunologic defense, the skin, and burn eschar is avascular. This can result in an increased risk for bacterial colonization and subsequent invasion, which can ultimately result in burn wound infection. This may be difficult to control due to difficulty immune cells and systemic antibiotics have in arriving to an avascular site [3]. Burn wound infections are a significant and serious complication occurring after thermal injury. Though the rate of burn wound infections has decreased, burn wound sepsis remains a substantial source of infection in this population [4].

Improvements in burn wound care, such as early excision and grafting, have resulted in decreased mortality [5]. Early excision and grafting is the standard of care at specialized burn centers in the United States. The benefit of topical antimicrobials, however, is that they can be used at all levels of care, even when surgery for excision and grafting is not available. Topicals such as honey have been in use since antiquity, and others for decades [4-11]. There are both animal studies and clinical studies that provide data about the morbidity and mortality benefits associated with use of various topical antimicrobial agents in the prevention and treatment of burn wound infections [5,12-17]. Another benefit of topical agents is that they can be delivered directly to the site of colonization or infection and can be used for both the prophylaxis and treatment of burn wound infections [18]. Agents such as silver sulfadiazine, silver nitrate, mupirocin, honey, mafenide acetate, and neomycin have been in use for years with variable amounts of objective data available to support their use (Table 1).

Though we have in vitro data about the topical antibiotics' general spectrum of activity, there are no established clinical breakpoints to determine whether an isolate is susceptible to a particular agent at concentrations expected at the wound surface. Bacteria with resistance to multiple systemic antimicrobials are increasing in prevalence worldwide, which raises concern for a subsequent increase in resistance to topical agents. The potential for resistant isolates makes choosing empiric systemic antimicrobial therapy in the burn unit more challenging and may reduce the number of available treatment options. Thus, the possibility of using topical agents for prophylaxis and treatment of burn wound infections is appealing, in particular given the ability to apply topical agents directly at the site of infection, avoiding potential systemic toxicities and the risk of systemic antibiotics not arriving through avascular tissue to the site of infection. However, some previous studies have already noted concern for resistance to topical agents as well to include emerging resistance of staphylococci to mupirocin and of Pseudomonas aeruginosa to silver sulfadiazine (Table 1) [9,18-21].

Prior studies assessing topical agent antimicrobial resistance profiles have used agar well diffusion and broth microdilution methods with data indicating an increase in resistance of MDR pathogens to topical antimicrobials as compared to non-MDR pathogens [8,22-24]. However, there are limited data comparing strain variability and systemic antimicrobial resistance to topical antimicrobial activity tested by various methods.

With MDR bacteria on the rise we designed this study to compare selected bacterial isolates against various topical antimicrobial agents using two methods, broth microdilution and agar well diffusion, in conjunction with phenotypic and genotypic testing to evaluate for clonal differences in activity and correlation with systemic resistance profiles and topical agent activity.

\section{Methods}

\subsection{Bacterial isolates}

A collection of bacterial isolates were obtained from patients admitted to the US Army Institute of Surgical Research (USAISR) Burn Center. The USAISR Burn Center is a 40-bed unit located within Brooke Army Medical Center that serves Department of Defense beneficiaries worldwide and the civilian population from within the southern Texas regional trauma system. Standard burn patient care includes resuscitation and stabilization upon arrival with early burn wound excision and skin grafting. Vancomycin and amikacin are administered routinely peri-operatively and various topical antimicrobials are used to include silver sulfadiazine, mafenide acetate, silver nitrate solution, and silver-impregnated dressings. The choice of the specific topical agent used is at staff discretion. Aggressive infection control is practiced in the center to include individual patient rooms, use of contact precautions, and strictly enforced handwashing.

The most common gram-negative pathogens recovered in our burn unit are Acinetobacter baumannii-calcoaceticus complex (ABC), extended-spectrum beta-lactamase (ESBL) producing Klebsiella pneumoniae, and $P$. aeruginosa, with methicillinresistant Staphylococcus aureus (MRSA) being a common gram-positive organism isolated. Isolates studied had been saved for performance improvement purposes and were stored in Microbank ${ }^{\circledR}$ Bacterial Preservation systems (ProLab Diagnostics, Austin, TX) at $-20^{\circ} \mathrm{C}$. The P. aeruginosa isolates were stored at room temperature on agar deeps. Isolates were passed twice on Trypticase ${ }^{\mathrm{TM}}$ Soy Agar with $5 \%$ Sheep Blood (TSA II) (BD Diagnostic) prior to use. Quality control (QC) bacteria (Escherichia coli ATCC ${ }^{\mathbb{R}}$ 25922, Enterococcus faecalis ATCC ${ }^{\mathbb{R}}$ 29212, P. aeruginosa ATCC ${ }^{\mathbb{R}} 27853$, and S. aureus ATCC ${ }^{\circledR}$ 29213) were obtained from the American Type Culture Collection (Manassas, VA). The QC organisms were maintained and cultured in the same manner as the test organisms.

\subsection{Antimicrobial susceptibility testing}

Using the Phoenix Automated Microbiology System (Becton, Dickinson and Co., Franklin Lakes, NJ) standard systemic antibiotic profiles were determined [25]. For P. aeruginosa and $A B C$, we defined MDR as resistance to all antimicrobials tested in a group for 3 or more groups among the aminoglycosides, betalactams, carbapenems, and fluoroquinolones [26]. All of the K. pneumoniae isolates used in this study were ESBL-producing. All of the $S$. aureus isolates were methicillin-resistant.

\subsection{Pulsed-field gel electrophoresis}

Pulsed-field gel electrophoresis (PFGE) was also performed for further clonal typing as described elsewhere [27-29]. The 
Table 1 - Description of topical antimicrobial agents evaluated.

\begin{tabular}{|c|c|c|c|c|c|c|}
\hline Topical agent & Mechanism of action & Spectrum of activity & Pros & Cons & $\begin{array}{l}\text { Resistance/ } \\
\text { other }\end{array}$ & Prior studies \\
\hline Bacitracin & $\begin{array}{l}\text { Polypeptide produced by Bacillus } \\
\text { subtilis that inhibits cell wall } \\
\text { synthesis and disrupts the } \\
\text { cytoplasmic membrane by } \\
\text { forming a complex with C55- } \\
\text { prenol pyrophosphate[8,9] }\end{array}$ & $\begin{array}{l}\text { Gram-positive organisms } \\
\text { especially Staphylococci and } \\
\text { beta-hemolytic Streptococci [8] } \\
\text { Inactive against most gram- } \\
\text { negative organisms including P. } \\
\text { aeruginosa [34] }\end{array}$ & Minimal absorption & $\begin{array}{l}\text { Rare anaphylaxis } \\
\text { and allergic contact } \\
\text { dermatitis [9] }\end{array}$ & $\begin{array}{l}\text { Rare resistant S. } \\
\text { aureus [9] }\end{array}$ & None available \\
\hline $\begin{array}{l}\text { Medical } \\
\text { grade honey }\end{array}$ & $\begin{array}{l}\text { Variable antimicrobial activity } \\
\text { among honeys collected from } \\
\text { natural environments [7] } \\
\text { Properties responsible for } \\
\text { antimicrobial activity include } \\
\text { high osmolarity, low pH (3.2- } \\
4.5) \text {, a thermolabile substance } \\
\text { called inhibine, and production } \\
\text { of hydrogen peroxide [7,35] } \\
\text { Also may have some anti- } \\
\text { inflammatory activity [36] }\end{array}$ & $\begin{array}{l}\text { Bactericidal against gram- } \\
\text { positive and gram-negative } \\
\text { organisms including P. } \\
\text { aeruginosa and MRSA }[35,37]\end{array}$ & $\begin{array}{l}\text { Manages superficial bacteria but } \\
\text { may also diffuse through skin to } \\
\text { deeper tissues [36] } \\
\text { Generally found to be soothing, } \\
\text { pain-relieving, and non- } \\
\text { irritating [36] } \\
\text { May promote healing of burn } \\
\text { wounds and reduce scarring [35] }\end{array}$ & $\begin{array}{l}\text { Food-grade honey is not a } \\
\text { sterile product; may contain } \\
\text { Bacillus spp. [38] Medical-grade } \\
\text { honey needs to be filtered and } \\
\text { gamma-irradiated } \\
\text { Avoid use in patients with } \\
\text { allergy to honey, bee products, } \\
\text { or bee stings [36] }\end{array}$ & $\begin{array}{l}\text { No reported } \\
\text { resistance [7] }\end{array}$ & $\begin{array}{l}\text { Honey helped burn } \\
\text { wounds to heal } \\
\text { earlier and with } \\
\text { fewer complications } \\
\text { than convention } \\
\text { treatment (silver } \\
\text { sulfadiazine) [35] } \\
\text { Most data available is } \\
\text { on Leptospermum spp. } \\
\text { honey (Manuka) }\end{array}$ \\
\hline $\begin{array}{l}\text { Mafenide } \\
\text { acetate } \\
\text { (Sulfamylon) }\end{array}$ & Inhibits nucleotide synthesis [8] & $\begin{array}{l}\text { Bacteriostatic against gram- } \\
\text { negative organisms including } P \text {. } \\
\text { aeruginosa and gram-positive } \\
\text { organisms }[13,39]\end{array}$ & $\begin{array}{l}11.1 \% \text { cream, } 5 \% \text { solution } \\
\text { Rapidly penetrates full } \\
\text { thickness eschar making it } \\
\text { effective in heavily colonized } \\
\text { wounds and established burn } \\
\text { wound infection }[3,5,33]\end{array}$ & $\begin{array}{l}11.1 \% \text { concentration is painful } \\
\text { when applied to the superficial } \\
\text { partial-thickness burns with } \\
\text { intact free nerve endings [3,40] } \\
\text { Can dry into a tenacious gum } \\
\text { (neosshar) that attaches to the } \\
\text { wound requiring hydrotherapy } \\
\text { to remove [41] } \\
5 \% \text { aqueous solution is less } \\
\text { painful and does not leave a } \\
\text { residue [42] } \\
\text { Absorbed systemically with } \\
\text { highest blood levels of mafenide } \\
\text { and its metabolite (p- } \\
\text { carboxybenzenesulfonamide) in } \\
\text { 2nd-4th hour resulting in } \\
\text { urinary alkalinization from } \\
\text { carbonic anhydrase inhibition } \\
\text { [43] } \\
\text { Possible metabolic acidosis, } \\
\text { especially in patients with } \\
\text { pulmonary dysfunction such as } \\
\text { atelectasis or pneumonia that } \\
\text { limits respiratory compensation } \\
\text { [14,40,44] } \\
\text { Electrolyte disturbances [45] } \\
7 \% \text { incidence of } \\
\text { hypersensitivity, usually a rash } \\
\text { [5] } \\
\text { Rapid absorption from the } \\
\text { tissue requires twice daily } \\
\text { application to keep levels high } \\
\text { enough for bacterial inhibition } \\
\text { [33] }\end{array}$ & $\begin{array}{l}\text { No resistance } \\
\text { reported to } P \text {. } \\
\text { aeruginosa [6] } \\
\text { Some resistance } \\
\text { described to } \\
\text { Providencia [5] }\end{array}$ & $\begin{array}{l}\text { Mortality benefit in } \\
\text { prevention of burn } \\
\text { wound sepsis } \\
\text { described in animal } \\
\text { models [13] } \\
\text { Reduction in } \\
\text { mortality and the rate } \\
\text { of invasive burn } \\
\text { wound infections in } \\
\text { patients from before } \\
\text { the introduction of } \\
\text { mafenide to after, } \\
\text { particularly in } \\
\text { patients with } 40-79 \% \\
\text { TBSA in one study [5] } \\
\text { and between } 20 \text { and } \\
59 \% \text { TBSA in another } \\
\text { study [14,15] } \\
\text { Found to be the most } \\
\text { effective topical agent } \\
\text { against A. baumannii } \\
\text { [18] } \\
\text { Poor correlation } \\
\text { between broth } \\
\text { microdilution and } \\
\text { agar well diffusion } \\
\text { [23] }\end{array}$ \\
\hline
\end{tabular}




\begin{tabular}{|c|c|c|c|c|c|c|}
\hline Mupirocin & $\begin{array}{l}\text { Pseudomonic acid, produced by } \\
\text { Pseudomonas fluorescens [19] } \\
\text { Inhibition of RNA and protein } \\
\text { synthesis by targeting the } \\
\text { isoleucine-binding site on the } \\
\text { isoleucyl-transfer-RNA } \\
\text { synthetase enzyme }[9,46,47]\end{array}$ & $\begin{array}{l}\text { Bactericidal at high } \\
\text { concentrations ( } 2 \% \text { formulation) } \\
\text { and after 24-36 h of exposure } \\
{[46]} \\
\text { Highly active against } \\
\text { streptococci and staphylococci } \\
\text { including MRSA [9]. Not active } \\
\text { against enterococci } \\
\text { Less effective against most } \\
\text { gram-negative bacilli and } \\
\text { anaerobes including K. } \\
\text { pneumoniae and P. aeruginosa [19] }\end{array}$ & $\begin{array}{l}\text { No systemic absorption of } \\
\text { mupirocin or its major } \\
\text { metabolite (monic acid) has } \\
\text { been detected with topical use } \\
\text { in healthy volunteers or } \\
\text { patients with epidermolysis } \\
\text { bullosa }[9,46] \\
\text { Can penetrate eschar [48] } \\
\text { Has been used successfully in } \\
\text { the treatment of MRSA-infected } \\
\text { burns wounds [49] }\end{array}$ & $\begin{array}{l}\text { Prolonged use may result in } \\
\text { overgrowth of non-susceptible } \\
\text { organisms, including fungi [9] }\end{array}$ & $\begin{array}{l}\text { Emergence of } \\
\text { resistant } \\
\text { staphylococci has } \\
\text { been described } \\
\text { worldwide }[9,19,20] \\
\text { Possible mechanism } \\
\text { of resistance is a } \\
\text { transmissible } \\
\text { plasmid [46] } \\
\text { No cross resistance } \\
\text { with other antibiotics } \\
\text { [50] }\end{array}$ & $\begin{array}{l}\text { Application of } \\
\text { mupirocin to burn } \\
\text { wounds rapidly } \\
\text { eradicated MRSA [48] } \\
\text { Good correlation } \\
\text { between broth } \\
\text { microdilution and } \\
\text { agar well diffusion } \\
\text { [23] }\end{array}$ \\
\hline Neomycin & $\begin{array}{l}\text { Aminoglycoside produced by } \\
\text { Streptomyces fradiae [51] } \\
\text { Inhibition of protein synthesis } \\
\text { at the } 30 \text { S subunit of the } \\
\text { bacterial ribosome [9] } \\
\text { May also inhibit bacterial DNA } \\
\text { polymerase }\end{array}$ & $\begin{array}{l}\text { Gram-negatives except } \\
\text { Pseudomonas aeruginosa and } \\
\text { anaerobes such as Bacteroides } \\
\text { spp. [51] } \\
\text { Staphylococci, not Streptococci and } \\
\text { gram-positive bacilli }\end{array}$ & $\begin{array}{l}\text { May enhance re- } \\
\text { epithelialization in wound } \\
\text { healing [34] }\end{array}$ & $\begin{array}{l}\text { Otoxicity and nephrotoxicity } \\
\text { with systemic use. Absorption } \\
\text { can occur through inflamed } \\
\text { skin but is negligible through } \\
\text { normal skin [9,51] } \\
\text { Allergic sensitization especially } \\
\text { when ointment is used for } \\
\text { prolonged time on inflamed or } \\
\text { denuded skin [51]. Related to } \\
\text { mast cell degranulation and } \\
\text { histamine release [9] }\end{array}$ & $\begin{array}{l}\text { Resistant strains of } E \text {. } \\
\text { coli, Klebsiella, and } \\
\text { Proteus spp. may } \\
\text { emerge [51] } \\
\text { Transfer of neomycin } \\
\text { resistance occurs in } \\
\text { hospital-acquired } \\
\text { isolates of S. aureus } \\
\text { Resistance may be } \\
\text { plasmid mediated, } \\
\text { and resistance to } \\
\text { other } \\
\text { aminoglycosides can } \\
\text { be transferred on the } \\
\text { same plasmid [9] }\end{array}$ & None available \\
\hline Polymyxin B & $\begin{array}{l}\text { Inhibits activity of endotoxins } \\
\text { [52] } \\
\text { Interacts with the outer } \\
\text { membrane of the gram- } \\
\text { negative cell wall and destroys } \\
\text { bacterial membranes with a } \\
\text { detergent-like mechanism }[8,52]\end{array}$ & $\begin{array}{l}\text { Gram-negative organisms } \\
\text { including P. aeruginosa [8] } \\
\text { No activity against gram- } \\
\text { positive organisms or fungi [9] }\end{array}$ & Little systemic absorption [9] & No data available & $\begin{array}{l}\text { Resistant strains of } A . \\
\text { baumannii are } \\
\text { emerging [18] }\end{array}$ & None available \\
\hline Silver nitrate & $\begin{array}{l}\text { Interferes with electron } \\
\text { transport inhibiting cellular } \\
\text { respiration and function }[8,17]\end{array}$ & $\begin{array}{l}\text { Gram-negative and gram- } \\
\text { positive organisms including } \\
\text { Pseudomonas spp. and S. aureus } \\
{[8,53]} \\
\text { Some activity against Candida } \\
\text { spp. }\end{array}$ & $\begin{array}{l}0.5 \% \text { aqueous solution } \\
\text { Reduces nutritional and } \\
\text { metabolic losses by decreasing } \\
\text { evaporative water loss }[3,33,54] \\
\text { Painless on application }[33]\end{array}$ & $\begin{array}{l}\text { Poor eschar penetration [3] so } \\
\text { can be used for prophylaxis but } \\
\text { not treatment of burn wound } \\
\text { infections [55] } \\
\text { Turns black upon contact with } \\
\text { tissues and can stain linens } \\
\text { [53,54,56,57] } \\
\text { Electrolyte disturbances due to } \\
\text { leeching of cations across the } \\
\text { wound into the hypotonic } \\
\text { solution, "sodium sink" } \\
{[3,6,20,33,40,54]} \\
\text { Aerobacter cloacae and some } \\
\text { other gram-negative bacteria } \\
\text { can convert the nitrate to nitrite } \\
\text { causing methemoglobinemia [3] } \\
\text { Problems with tissue irritation } \\
\text { and delayed wound healing } \\
\text { have been reported [3,57] }\end{array}$ & $\begin{array}{l}\text { Acquired resistance is } \\
\text { uncommon [33,58] } \\
\text { Resistance is often } \\
\text { unstable and isolates } \\
\text { can revert back to } \\
\text { sensitive [59] }\end{array}$ & $\begin{array}{l}\text { Has been used in } \\
\text { burn treatment since } \\
\text { at least the 18th } \\
\text { century, initially in a } \\
\text { hardened form called } \\
\text { lunar caustic [10] } \\
\text { Reduced mortality in } \\
\text { burned mice with P. } \\
\text { aeruginosa infection } \\
\text { by } 30 \% \text { [16] } \\
\text { Application to }>40 \% \\
\text { TBSA wounds } \\
\text { delayed sepsis and } \\
\text { reduced mortality } \\
\text { from } 81 \% \text { to } 33 \% \text { [54] }\end{array}$ \\
\hline
\end{tabular}


Table 1 (Continued)

Topical agent

Mechanism of action

Spectrum of activity

Pros

Cons

Resistance/

Prior studies

\begin{tabular}{|c|c|c|c|c|c|c|}
\hline $\begin{array}{l}\text { Silver Sulfadiazine } \\
\text { (Silvadene) }\end{array}$ & $\begin{array}{l}\text { Interferes with electron } \\
\text { transport and nucleotide } \\
\text { synthesis [8] } \\
\text { Binds to bacterial cell } \\
\text { membranes and cell wall, } \\
\text { penetrates the cell, and } \\
\text { denatures bacterial DNA and } \\
\text { RNA resulting in inhibition of } \\
\text { replication }[9,17]\end{array}$ & $\begin{array}{l}\text { Bactericidal to gram-negative } \\
\text { and gram-positive organisms } \\
\text { including Pseudomonas spp. and } \\
\text { S. aureus (MRSA) [3,20] } \\
\text { Some activity against Candida } \\
\text { spp. and herpesviruses at high } \\
\text { concentrations [9] }\end{array}$ & $\begin{array}{l}\text { Combination of the silver ion } \\
\text { and sulfadiazine in a } 1 \% \text { water } \\
\text { soluble cream introduced in } \\
1968 \text { [3] } \\
\text { Painless on application [60] } \\
\text { Accelerated deep dermal wound } \\
\text { healing and reduced conversion } \\
\text { rate of deep dermal wounds to } \\
\text { full-thickness skin wounds [17] } \\
\text { Delayed eschar separation [17] }\end{array}$ & $\begin{array}{l}\text { Poor eschar penetration } \\
\text { Reversible granulocyte } \\
\text { depression especially in }>30 \% \\
\text { TBSA burns [3,6,9]. This occurs } \\
\text { early in therapy (postburn day } \\
\text { 2) and mainly affects mature } \\
\text { neutrophils though has not } \\
\text { been shown to increase risk of } \\
\text { infectious complications [61] } \\
\text { Not very effective in established } \\
\text { infection due to minimal eschar } \\
\text { penetration [49] } \\
\text { Appears as a thick creamy } \\
\text { exudates on the wound, which } \\
\text { can be confused with pus [3,53] } \\
\text { Rare hypersensitivity reactions } \\
\text { to sulfa moiety reported [33,62] } \\
\text { and rare hemolysis in setting of } \\
\text { G6PD deficiency [21] } \\
\text { Systemic absorption especially } \\
\text { in more vascular partial- } \\
\text { thickness burns [21,63] though } \\
\text { an experimental model using } \\
\text { radioactive silver sulfadiazine } \\
\text { showed silver only in the skin } \\
\text { and not in the blood/organs [53] } \\
\text { Rare argyrosis [63] if silver levels } \\
\text { are many times normal [21] }\end{array}$ & $\begin{array}{l}\text { Resistant to most } \\
\text { Enterobacter cloacae } \\
\text { and some } \\
\text { Pseudomonas spp. [5] } \\
\text { Plasmid-mediated } \\
\text { resistance against } \\
\text { some gram-negatives } \\
\text { including A. } \\
\text { baumannii and P. } \\
\text { aeruginosa has been } \\
\text { reported in burn } \\
\text { patients }[9,18,21]\end{array}$ & $\begin{array}{l}\text { Reduced mortality in } \\
\text { burned mice with P. } \\
\text { aeruginosa infection } \\
\text { by } 60-75 \%[16] \\
\text { Poor correlation } \\
\text { between broth } \\
\text { microdilution and } \\
\text { agar well diffusion } \\
\text { [23] }\end{array}$ \\
\hline $\begin{array}{l}\text { Triple antibiotic } \\
\text { ointment (Neomycin, } \\
\text { Polymyxin B, bacitracin) }\end{array}$ & $\begin{array}{l}\text { Antimicrobial activity has been } \\
\text { shown to reside in the } \\
\text { neomycin component [52] }\end{array}$ & $\begin{array}{l}\text { Moderate activity against a } \\
\text { variety of burn isolates, but has } \\
\text { poor activity against } P \text {. } \\
\text { aeruginosa [52] }\end{array}$ & No data available & No data available & No data available & None available \\
\hline
\end{tabular}




\begin{tabular}{|c|c|c|c|c|c|c|c|c|c|c|c|c|c|c|c|c|c|c|c|c|c|c|c|c|c|c|c|c|c|}
\hline \multirow{2}{*}{$\begin{array}{l}\text { MRSA } \\
\text { PFT }\end{array}$} & \multicolumn{9}{|c|}{ Broth microdilution } & \multicolumn{8}{|c|}{ Agar well diffusion } & \multicolumn{12}{|c|}{ Systemic antimicrobial agents } \\
\hline & MIC & BAC & MUP & NEO & POL & SN & ss & MA & $\mathrm{H}$ & AWD & BAC & MUP & $\mathrm{B} / \mathrm{N} / \mathrm{P}$ & SN & ss & MA & $\mathrm{H}$ & Susc & Clin & Ery & Gent & Levo & Lin & Mox & Q/D & Rif & Tet & $T / S$ & Vanc \\
\hline 1 & & $>256$ & 1 & 64 & 32 & 8 & 32 & 1024 & 5 & & 9 & 150 & 9 & 12 & 22 & 34 & 22 & & $\mathrm{R}$ & $\mathrm{R}$ & $\mathrm{s}$ & $\mathrm{R}$ & $\mathrm{s}$ & $\mathrm{R}$ & $\mathrm{s}$ & $\mathrm{s}$ & $\mathrm{s}$ & $\mathrm{s}$ & $\mathrm{s}$ \\
\hline 1 & & $>256$ & 2 & 128 & 16 & 8 & 32 & 1024 & 5 & & 9 & 150 & 9 & 13 & 22 & 34 & 21 & & $\mathrm{R}$ & $\mathrm{R}$ & $\mathrm{s}$ & $\mathrm{R}$ & $\mathrm{s}$ & I & $\mathrm{s}$ & $\mathrm{s}$ & $\mathrm{s}$ & $\mathrm{s}$ & $\mathrm{s}$ \\
\hline 1 & & $>256$ & 2 & 64 & 32 & 16 & 32 & 1024 & 10 & & 9 & 62 & 9 & 13 & 23 & 36 & 23 & & $\mathrm{R}$ & $\mathrm{R}$ & $\mathrm{s}$ & $\mathrm{R}$ & $\mathrm{s}$ & I & $\mathrm{s}$ & $\mathrm{s}$ & $\mathrm{s}$ & $\mathrm{S}$ & $\mathrm{s}$ \\
\hline 1 & & $>256$ & 1 & 32 & 16 & 8 & 32 & 512 & 5 & & 9 & 150 & 9 & 11 & 23 & 35 & 23 & & $\mathrm{R}$ & $\mathrm{R}$ & $\mathrm{s}$ & $\mathrm{s}$ & I & $\mathrm{s}$ & $\mathrm{s}$ & $\mathrm{s}$ & $\mathrm{s}$ & $\mathrm{s}$ & $\mathrm{s}$ \\
\hline 1 & & $>256$ & $>128$ & 64 & 16 & 16 & 32 & 512 & 15 & & 9 & 38 & 9 & 12 & 22 & 33 & 23 & & $\mathrm{x}$ & $\mathrm{R}$ & $\mathrm{R}$ & $\mathrm{R}$ & $\mathrm{s}$ & $\mathrm{R}$ & $\mathrm{s}$ & $\mathrm{s}$ & $\mathrm{s}$ & $\mathrm{S}$ & $\mathrm{s}$ \\
\hline 1 & & $>256$ & 1 & 64 & 16 & 16 & 32 & 1024 & 5 & & 9 & 150 & 9 & 13 & 21 & 36 & 22 & & $\mathrm{R}$ & $\mathrm{R}$ & $\mathrm{s}$ & $\mathrm{R}$ & $\mathrm{S}$ & $\mathrm{s}$ & $\mathrm{s}$ & $\mathrm{s}$ & $\mathrm{s}$ & $\mathrm{S}$ & $\mathrm{s}$ \\
\hline 1 & & $>256$ & 1 & 64 & 16 & 16 & 32 & 1024 & 10 & & 9 & 150 & 9 & 12 & 21 & 33 & 22 & & $\mathrm{x}$ & $\mathrm{R}$ & $\mathrm{s}$ & $\mathrm{R}$ & $\mathrm{s}$ & I & $\mathrm{s}$ & $\mathrm{s}$ & $\mathrm{s}$ & $\mathrm{S}$ & $\mathrm{s}$ \\
\hline 1 & & $>256$ & 2 & $>1024$ & 16 & 8 & 32 & 512 & 20 & & 9 & 150 & 9 & 13 & 23 & 34 & 23 & & $\mathrm{x}$ & $\mathrm{R}$ & $\mathrm{s}$ & $\mathrm{R}$ & $\mathrm{s}$ & $\mathrm{R}$ & $\mathrm{s}$ & $\mathrm{S}$ & $\mathrm{s}$ & $\mathrm{S}$ & $\mathrm{s}$ \\
\hline 1 & & $>256$ & 1 & 256 & 16 & 16 & 32 & 512 & 5 & & 9 & 150 & 9 & 13 & 24 & 34 & 22 & & $\mathrm{x}$ & $\mathrm{R}$ & $\mathrm{s}$ & $\mathrm{R}$ & $\mathrm{S}$ & $\mathrm{R}$ & $\mathrm{s}$ & $\mathrm{s}$ & $\mathrm{s}$ & $\mathrm{S}$ & $\mathrm{s}$ \\
\hline 1 & & $>256$ & 1 & 64 & 16 & 16 & 32 & 512 & 10 & & 9 & 150 & 9 & 12 & 22 & 32 & 24 & & $\mathrm{R}$ & $\mathrm{R}$ & $\mathrm{s}$ & $\mathrm{R}$ & $\mathrm{s}$ & I & $\mathrm{s}$ & $\mathrm{s}$ & $\mathrm{s}$ & $\mathrm{S}$ & $\mathrm{S}$ \\
\hline $1 \mathrm{a}$ & & $>256$ & 2 & 128 & 16 & 32 & 64 & 1024 & 15 & & 9 & 150 & 9 & 12 & 23 & 31 & 22 & & $\mathrm{x}$ & $\mathrm{R}$ & $\mathrm{s}$ & $\mathrm{R}$ & $\mathrm{S}$ & $\mathrm{R}$ & $\mathrm{s}$ & $\mathrm{s}$ & $\mathrm{s}$ & $\mathrm{s}$ & $\mathrm{s}$ \\
\hline $1 \mathrm{c}$ & & $>256$ & 1 & 128 & 16 & 8 & 32 & 1024 & 5 & & 9 & 150 & 9 & 13 & 24 & 34 & 23 & & $\mathrm{x}$ & $\mathrm{R}$ & $\mathrm{s}$ & $\mathrm{R}$ & $\mathrm{s}$ & I & $\mathrm{s}$ & $\mathrm{s}$ & $\mathrm{s}$ & $\mathrm{S}$ & $\mathrm{s}$ \\
\hline $1 \mathrm{c}$ & & $>256$ & 1 & 32 & 32 & 8 & 32 & 512 & 15 & & 9 & 150 & 9 & 13 & 23 & 34 & 23 & & $\mathrm{R}$ & $\mathrm{R}$ & $\mathrm{s}$ & $\mathrm{R}$ & $\mathrm{S}$ & I & $\mathrm{s}$ & $\mathrm{s}$ & $\mathrm{s}$ & S & $\mathrm{s}$ \\
\hline 3 & & $>256$ & 2 & 32 & 16 & 16 & 64 & 1024 & 15 & & 9 & 150 & 9 & 13 & 21 & 33 & 24 & & $\mathrm{R}$ & $\mathrm{R}$ & $\mathrm{s}$ & $\mathrm{s}$ & $\mathrm{S}$ & $\mathrm{s}$ & I & $\mathrm{s}$ & $\mathrm{s}$ & S & $\mathrm{s}$ \\
\hline 4 & & 32 & 0 & 256 & 32 & 16 & 32 & 1024 & 5 & & 9 & 150 & 9 & 12 & 21 & 28 & 21 & & $\mathrm{~s}$ & $\mathrm{~s}$ & $\mathrm{R}$ & $\mathrm{R}$ & $\mathrm{s}$ & $\mathrm{s}$ & $\mathrm{s}$ & $\mathrm{S}$ & $\mathrm{R}$ & $\mathrm{R}$ & $\mathrm{s}$ \\
\hline USA 300 & & $>256$ & 0.12 & 16 & 64 & 16 & 32 & 1024 & 15 & & 9 & 150 & 9 & 12 & 23 & 33 & 22 & & $\mathrm{x}$ & $\mathrm{R}$ & $\mathrm{s}$ & I & $\mathrm{s}$ & $\mathrm{s}$ & $\mathrm{s}$ & $\mathrm{s}$ & $\mathrm{s}$ & $\mathrm{S}$ & $\mathrm{s}$ \\
\hline USA 300 & & $>256$ & 0.12 & 512 & 64 & 16 & 32 & 1024 & 10 & & 9 & 150 & 9 & 12 & 23 & 32 & 23 & & $\mathrm{x}$ & $\mathrm{R}$ & $\mathrm{s}$ & $\mathrm{s}$ & $\mathrm{s}$ & $\mathrm{s}$ & $\mathrm{s}$ & $\mathrm{s}$ & I & $\mathrm{S}$ & $\mathrm{s}$ \\
\hline USA 300 & & $>256$ & 0.25 & $>1024$ & 16 & 16 & 32 & 1024 & 15 & & 9 & 150 & 9 & 13 & 22 & 31 & 23 & & $\mathrm{x}$ & $\mathrm{R}$ & $\mathrm{s}$ & $\mathrm{s}$ & $\mathrm{s}$ & $\mathrm{s}$ & $\mathrm{s}$ & $\mathrm{s}$ & I & $\mathrm{x}$ & $\mathrm{s}$ \\
\hline USA 300 & & $>256$ & 0.12 & 512 & 32 & 16 & 64 & 1024 & 15 & & 9 & 150 & 9 & 12 & 23 & 36 & 23 & & $\mathrm{x}$ & $\mathrm{R}$ & $\mathrm{s}$ & $\mathrm{s}$ & $\mathrm{s}$ & $\mathrm{s}$ & $\mathrm{s}$ & $\mathrm{s}$ & $\mathrm{s}$ & $\mathrm{s}$ & $\mathrm{s}$ \\
\hline \multirow[t]{4}{*}{ USA 300} & & 32 & 0.12 & $<0.5$ & 16 & 16 & 32 & 512 & 5 & & 9 & 150 & 20 & 13 & 25 & 36 & 24 & & s & s & s & s & S & s & s & S & s & S & s \\
\hline & $\mu \mathrm{g} / \mathrm{ml}$ & & & & & & & & & $\mathrm{mm}$ & & & & & & & & & & & & & & & & & & & \\
\hline & 50 & $>256$ & 1 & 64 & 16 & 16 & 32 & 1024 & 10 & Mean & 9 & 140 & 9.6 & 12.5 & 22.6 & 33.5 & 22.7 & \%susc & 20 & 10 & 90 & 30 & 95 & 45 & 95 & 100 & 85 & 95 & 100 \\
\hline & 90 & $>256$ & 2 & 512 & 32 & 16 & 64 & 1024 & 15 & Range & 9 & $38-150$ & $9-20$ & $11-13$ & $21-25$ & $28-36$ & $21-24$ & & & & & & & & & & & & \\
\hline $\begin{array}{l}50=\mathrm{M} \\
\text { type; } \\
\text { AWD = } \\
\text { Levo = } \\
\text { suscep }\end{array}$ & 10 & $\begin{array}{l}\text { num } \\
\text { num } \\
\text { diffus } \\
\text { n; Lir } \\
\text { thos }\end{array}$ & $\begin{array}{l}\text { centr } \\
\text { iibitor }\end{array}$ & Mox = & $=\operatorname{mox}$ & xifloxa & ecific & $\begin{array}{l}\text { pocit } \\
\text { Q/D }\end{array}$ & & of & 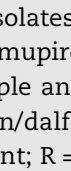 & (nin, & $=\mathrm{MI}$ & $\begin{array}{l}=\operatorname{mini} \\
\text { cin; } P \\
\text { Susc = } \\
\text { npin; }\end{array}$ & $\begin{array}{l}=\mathrm{pol} \\
\mathrm{mic} \\
=\mathrm{tet}\end{array}$ & cline & $\mathrm{s}=\mathrm{tr}$ & . & $\begin{array}{l}\text { e; SS } \\
=\mathrm{clin} \\
\mathrm{rm} / \mathrm{su}\end{array}$ & than & $\begin{array}{l}\text { th of } \\
\text { ver su } \\
\text { nycin; } \\
\text { netho }\end{array}$ & $\begin{array}{l}90 \% \text { o } \\
\text { ulfadi } \\
\text { Ery = } \\
\text { xazol }\end{array}$ & $\begin{array}{l}\text { of isol } \\
\text { liazine } \\
=\text { erytl } \\
\text { le; Va }\end{array}$ & $\begin{array}{l}\text { lates } \\
\text { e; MA } \\
\text { throm } \\
\text { Janc = }\end{array}$ & $\begin{array}{l}\text { nycin; } \\
=\text { vanc }\end{array}$ & $\begin{array}{l}\text { d; PFT } \\
\text { afenid } \\
\text { Gent } \\
\text { comyc }\end{array}$ & $\begin{array}{l}T=\text { pul } \\
\text { de; H } \\
t=\text { gen } \\
\text { cin; } \%\end{array}$ & \%sus & $\begin{array}{l}\text { field } \\
\text { oney; } \\
\text { nicin; } \\
c=\%\end{array}$ \\
\hline
\end{tabular}


Table 3 - Pulsed-field type, broth microdilution, agar well diffusion, and antibiotic resistance profiles for Klebsiella pneumoniae isolates from burn patients.

\begin{tabular}{|c|c|c|c|c|c|c|c|c|c|c|c|c|c|c|c|c|c|c|c|c|c|c|c|c|c|c|c|c|}
\hline \multirow{2}{*}{$\begin{array}{l}\text { Kleb } \\
\text { PFT }\end{array}$} & \multicolumn{9}{|c|}{ Broth microdilution } & \multicolumn{8}{|c|}{ Agar well diffusion } & \multicolumn{11}{|c|}{ Antimicrobial susceptibility } \\
\hline & MIC & BAC & MUP & NEO & POL & SN & ss & MA & $\mathrm{H}$ & AWD & BAC & MUP & $\mathrm{B} / \mathrm{N} / \mathrm{P}$ & SN & SS & MA & $\mathrm{H}$ & Susc & Ami & Gent & Tobra & Cefep & Ceftaz & $\mathrm{P} / \mathrm{T}$ & Levo & Cipro & $\operatorname{Imi}$ & Mero \\
\hline 1 & & $>256$ & $>128$ & 1 & 2 & 16 & 64 & 1024 & 25 & & 9 & 32 & 18 & 12 & 22 & 26 & 16 & & $\mathrm{~s}$ & $\mathrm{R}$ & I & $\mathrm{R}$ & $\mathrm{x}$ & $\mathrm{x}$ & $\mathrm{R}$ & $\mathrm{R}$ & $\mathrm{s}$ & $\mathrm{s}$ \\
\hline $1 \mathrm{C}$ & & $>256$ & $>128$ & 1 & $<0.5$ & 8 & 32 & 512 & 25 & & 9 & 27 & 19 & 12 & 20 & 27 & 17 & & $\mathrm{~s}$ & $\mathrm{R}$ & I & $\mathrm{R}$ & $\mathrm{R}$ & $\mathrm{s}$ & $\mathrm{R}$ & $\mathrm{R}$ & $\mathrm{s}$ & $\mathrm{s}$ \\
\hline $1 \mathrm{C}$ & & $>256$ & $>128$ & 2 & 16 & 16 & 64 & 2048 & 20 & & 9 & 30 & 17 & 11 & 18 & 23 & 16 & & $\mathrm{~s}$ & $\mathrm{R}$ & $\mathrm{R}$ & $\mathrm{R}$ & $\mathrm{x}$ & I & $\mathrm{R}$ & $\mathrm{R}$ & $\mathrm{s}$ & $\mathrm{s}$ \\
\hline $1 \mathrm{C}$ & & $>256$ & $>128$ & $<0.5$ & $<0.5$ & 8 & 32 & 1024 & 25 & & 9 & 32 & 20 & 13 & 21 & 27 & 17 & & $\mathrm{~s}$ & $\mathrm{R}$ & I & $\mathrm{R}$ & $\mathrm{R}$ & I & $\mathrm{R}$ & $\mathrm{R}$ & $\mathrm{s}$ & $\mathrm{s}$ \\
\hline $1 \mathrm{C}$ & & $>256$ & $>128$ & $<0.5$ & 1 & 8 & 32 & 1024 & 25 & & 9 & 28 & 18 & 12 & 18 & 25 & 16 & & $\mathrm{~s}$ & $\mathrm{R}$ & I & $\mathrm{R}$ & $\mathrm{R}$ & $\mathrm{R}$ & $\mathrm{R}$ & $\mathrm{R}$ & $\mathrm{s}$ & $\mathrm{s}$ \\
\hline 1D & & $>256$ & $>128$ & $<0.5$ & $<0.5$ & 8 & 32 & 512 & 25 & & 9 & 27 & 18 & 6 & 9 & 25 & 17 & & $\mathrm{R}$ & $\mathrm{R}$ & $\mathrm{R}$ & $\mathrm{R}$ & $\mathrm{R}$ & $\mathrm{R}$ & $\mathrm{R}$ & $\mathrm{R}$ & $\mathrm{s}$ & S \\
\hline 2 & & $>256$ & $>128$ & 1 & $<0.5$ & 8 & 32 & 1024 & 25 & & 9 & 27 & 20 & 8 & 15 & 29 & 17 & & $\mathrm{R}$ & $\mathrm{R}$ & $\mathrm{R}$ & $\mathrm{R}$ & $\mathrm{x}$ & $\mathrm{R}$ & $\mathrm{R}$ & $\mathrm{R}$ & S & S \\
\hline 2 & & $>256$ & $>128$ & $<0.5$ & 16 & 8 & 32 & 1024 & 25 & & 9 & 34 & 19 & 13 & 21 & 25 & 17 & & $\mathrm{R}$ & $\mathrm{R}$ & $\mathrm{R}$ & $\mathrm{R}$ & $x$ & $\mathrm{R}$ & $\mathrm{R}$ & $\mathrm{R}$ & $\mathrm{s}$ & S \\
\hline 2 & & $>256$ & $>128$ & 1 & 32 & 8 & 32 & 1024 & 25 & & 9 & 36 & 20 & 13 & 20 & 23 & 19 & & $\mathrm{R}$ & $\mathrm{R}$ & $\mathrm{R}$ & $\mathrm{R}$ & $\mathrm{R}$ & $\mathrm{x}$ & S & I & $\mathrm{s}$ & S \\
\hline $2 B$ & & $>256$ & $>128$ & 1 & 32 & 16 & 64 & 1024 & 25 & & 9 & 31 & 21 & 12 & 21 & 23 & 18 & & $\mathrm{~s}$ & $\mathrm{R}$ & I & $\mathrm{R}$ & $\mathrm{R}$ & $\mathrm{R}$ & $\mathrm{R}$ & $\mathrm{R}$ & $\mathrm{s}$ & S \\
\hline $2 \mathrm{C}$ & & $>256$ & $>128$ & $<0.5$ & $<0.5$ & 8 & 32 & 1024 & 25 & & 9 & 31 & 17 & 6 & 12 & 24 & 17 & & $\mathrm{~S}$ & $\mathrm{R}$ & $\mathrm{R}$ & $\mathrm{R}$ & $\mathrm{R}$ & I & S & $\mathrm{R}$ & $\mathrm{s}$ & S \\
\hline $2 C$ & & $>256$ & $>128$ & $<0.5$ & $<0.5$ & 8 & 32 & 2048 & 25 & & 9 & 33 & 20 & 6 & 12 & 23 & 17 & & $\mathrm{~s}$ & $\mathrm{R}$ & $\mathrm{R}$ & $\mathrm{R}$ & $\mathrm{R}$ & $\mathrm{R}$ & S & $\mathrm{R}$ & $\mathrm{s}$ & S \\
\hline $2 C$ & & $>256$ & $>128$ & $<0.5$ & $<0.5$ & 8 & 32 & 512 & 25 & & 9 & 24 & 17 & 6 & 9 & 32 & 18 & & $\mathrm{~s}$ & $\mathrm{R}$ & $\mathrm{R}$ & $\mathrm{R}$ & $\mathrm{R}$ & $\mathrm{x}$ & $\mathrm{R}$ & $\mathrm{R}$ & $\mathrm{s}$ & S \\
\hline 38 & & $>256$ & $>128$ & 32 & 8 & 8 & 32 & 2048 & 25 & & 9 & 43 & 9 & 9 & 21 & 23 & 18 & & $\mathrm{R}$ & $\mathrm{R}$ & $\mathrm{R}$ & $\mathrm{R}$ & $\mathrm{R}$ & s & S & $\mathrm{s}$ & $\mathrm{s}$ & S \\
\hline 3B & & $>256$ & $>128$ & $<0.5$ & 16 & 8 & 32 & 2048 & 25 & & 9 & 37 & 21 & 15 & 20 & 20 & 17 & & $\mathrm{~s}$ & $\mathrm{R}$ & $\mathrm{R}$ & $\mathrm{R}$ & $\mathrm{R}$ & $\mathrm{R}$ & $\mathrm{s}$ & $\mathrm{R}$ & $\mathrm{s}$ & $\mathrm{s}$ \\
\hline 5 & & $>256$ & $>128$ & 2 & 2 & 8 & 32 & 1024 & 25 & & 9 & 33 & 15 & 10 & 20 & 21 & 16 & & $\mathrm{~s}$ & $\mathrm{R}$ & $\mathrm{R}$ & $\mathrm{R}$ & $\mathrm{R}$ & $\mathrm{R}$ & S & $\mathrm{R}$ & s & S \\
\hline 10 & & $>256$ & $>128$ & $<0.5$ & 1 & 8 & 32 & 2048 & 25 & & 9 & 30 & 17 & 10 & 18 & 19 & 16 & & $\mathrm{~s}$ & $\mathrm{R}$ & $\mathrm{R}$ & $\mathrm{R}$ & $\mathrm{R}$ & $\mathrm{R}$ & $\mathrm{R}$ & $\mathrm{R}$ & $\mathrm{s}$ & $\mathrm{s}$ \\
\hline 16 & & $>256$ & $>128$ & 2 & 2 & 16 & 64 & 2048 & 25 & & 9 & 28 & 16 & 10 & 18 & 26 & 16 & & $\mathrm{~s}$ & $\mathrm{R}$ & $\mathrm{R}$ & $\mathrm{R}$ & $\mathrm{R}$ & $\mathrm{R}$ & S & $\mathrm{R}$ & $\mathrm{s}$ & S \\
\hline 17 & & $>256$ & $>128$ & $<0.5$ & 16 & 8 & 32 & 2048 & 20 & & 9 & 29 & 21 & 12 & 21 & 20 & 18 & & $\mathrm{R}$ & $\mathrm{R}$ & $\mathrm{R}$ & $\mathrm{R}$ & $\mathrm{R}$ & $\mathrm{x}$ & $\mathrm{R}$ & $\mathrm{R}$ & $\mathrm{s}$ & $\mathrm{s}$ \\
\hline 18 & & $>256$ & $>128$ & 2 & $<0.5$ & 32 & 32 & 2048 & 20 & & 9 & 31 & 15 & 9 & 15 & 14 & 17 & & $\mathrm{~s}$ & $\mathrm{R}$ & $\mathrm{R}$ & $\mathrm{R}$ & $\mathrm{R}$ & $\mathrm{x}$ & $\mathrm{R}$ & $\mathrm{R}$ & $\mathrm{s}$ & S \\
\hline $18 \mathrm{~A}$ & & $>256$ & $>128$ & 2 & 16 & 16 & 32 & 1024 & 20 & & 9 & 34 & 16 & 8 & 13 & 21 & 17 & & $\mathrm{R}$ & $\mathrm{R}$ & $\mathrm{R}$ & $\mathrm{R}$ & $\mathrm{R}$ & $\mathrm{x}$ & $\mathrm{s}$ & $\mathrm{s}$ & $\mathrm{s}$ & S \\
\hline 24 & & $>256$ & $>128$ & $<0.5$ & 1 & 8 & 32 & 2048 & 25 & & 12 & 28 & 17 & 11 & 16 & 21 & 16 & & $\mathrm{~s}$ & $\mathrm{R}$ & $\mathrm{R}$ & $\mathrm{R}$ & $\mathrm{R}$ & $\mathrm{R}$ & S & $\mathrm{s}$ & $\mathrm{s}$ & S \\
\hline & $\mu \mathrm{g} / \mathrm{ml}$ & & & & & & & & & $\mathrm{mm}$ & & & & & & & & & & & & & & & & & & \\
\hline & 50 & $>256$ & $>128$ & $<0.5$ & 1 & 8 & 32 & 1024 & 25 & Mean & 9.1 & 31.1 & 17.8 & 10.2 & 17.3 & 23.5 & 17 & \%susc & 68 & 0 & 0 & 0 & 0 & 13 & 41 & 14 & 100 & 100 \\
\hline & 90 & $>256$ & $>128$ & 2 & 16 & 16 & 64 & 2048 & 25 & Range & $9-12$ & $24-43$ & $9-21$ & 6-15 & $9-22$ & 14-32 & $16-19$ & & & & & & & & & & & \\
\hline
\end{tabular}

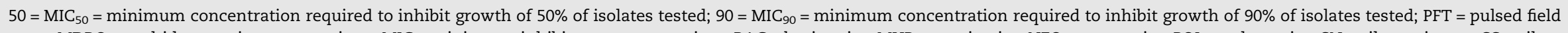

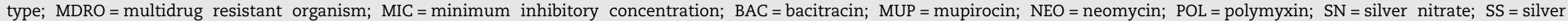

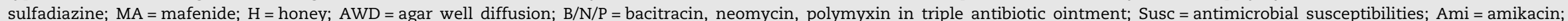

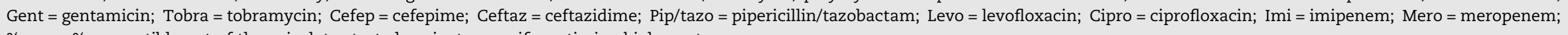
$\%$ susc $=\%$ susceptible out of those isolates tested against a specific antimicrobial agent. 
Table 4 - Pulsed-field type, broth microdilution, agar well diffusion, and antibiotic resistance profiles for Pseudomonas aeruginosa isolates from burn patients.

\begin{tabular}{|c|c|c|c|c|c|c|c|c|c|c|c|c|c|c|c|c|c|c|c|c|c|c|c|c|c|c|c|c|c|c|}
\hline \multirow{2}{*}{\multicolumn{2}{|c|}{$\begin{array}{l}\text { PS } \\
\text { PFT MDRO }\end{array}$}} & \multicolumn{9}{|c|}{ Broth microdilution } & \multicolumn{8}{|c|}{ Agar well diffusion } & \multicolumn{12}{|c|}{ Antimicrobial agents } \\
\hline & & MIC & BAC & MUP & NEO & POL & SN & ss & MA & $\mathrm{H}$ & AWD & BAC & MUP & $\mathrm{B} / \mathrm{N} / \mathrm{P}$ & SN & ss & MA & $\mathrm{H}$ & Susc & Ami & Gent & Tobra & Amp/S & Cefep & Ceftaz & $\mathrm{P} / \mathrm{T}$ & Levo & Cipro & Imi & Mero \\
\hline 1 & Yes & & $>256$ & $>128$ & 16 & 2 & 8 & 32 & 1024 & 10 & & 9 & 17 & 9 & 9 & 15 & 26 & 18 & & $\mathrm{~s}$ & $\mathrm{~s}$ & $\mathrm{~s}$ & $\mathrm{R}$ & $\mathrm{R}$ & $\mathrm{R}$ & $\mathrm{R}$ & $\mathrm{R}$ & $\mathrm{R}$ & $\mathrm{R}$ & $\mathrm{R}$ \\
\hline 1 & Yes & & $>256$ & $>128$ & 16 & 4 & 8 & 32 & 1024 & 10 & & 9 & 20 & 9 & 11 & 20 & 33 & 21 & & $\mathrm{~s}$ & $\mathrm{R}$ & $\mathrm{s}$ & $\mathrm{x}$ & $\mathrm{R}$ & $\mathrm{R}$ & $\mathrm{x}$ & $\mathrm{R}$ & $\mathrm{R}$ & $\mathrm{R}$ & I \\
\hline 1 & No & & $>256$ & $>128$ & 8 & 2 & 8 & 32 & 2048 & 10 & & 9 & 22 & 10 & 11 & 16 & 27 & 15 & & $\mathrm{~s}$ & $\mathrm{~s}$ & $\mathrm{~s}$ & $\mathrm{R}$ & $\mathrm{R}$ & $\mathrm{R}$ & $\mathrm{R}$ & $\mathrm{R}$ & $\mathrm{R}$ & $\mathrm{s}$ & $\mathrm{s}$ \\
\hline 1 & Yes & & $>256$ & $>128$ & 16 & 1 & 8 & 32 & 1024 & 10 & & 9 & 18 & 10 & 10 & 15 & 10 & 17 & & $S$ & I & $\mathrm{S}$ & $\mathrm{R}$ & $\mathrm{R}$ & $\mathrm{R}$ & $\mathrm{R}$ & $\mathrm{R}$ & $\mathrm{R}$ & $\mathrm{R}$ & $\mathrm{R}$ \\
\hline $1 \mathrm{~A}$ & Yes & & $>256$ & $>128$ & 16 & 1 & 8 & 16 & 1024 & 10 & & 9 & 18 & 9 & 9 & 17 & 26 & 15 & & $S$ & I & $\mathrm{s}$ & $\mathrm{R}$ & $\mathrm{R}$ & $\mathrm{R}$ & $\mathrm{R}$ & $\mathrm{R}$ & $\mathrm{R}$ & $\mathrm{R}$ & $\mathrm{R}$ \\
\hline $1 \mathrm{~A}$ & Yes & & $>256$ & $>128$ & 8 & 2 & 8 & 32 & 1024 & 10 & & 9 & 23 & 10 & 10 & 16 & 30 & 19 & & $S$ & $\mathrm{~s}$ & $\mathrm{~s}$ & $\mathrm{R}$ & $\mathrm{R}$ & $\mathrm{R}$ & $\mathrm{R}$ & $\mathrm{R}$ & $\mathrm{R}$ & $\mathrm{R}$ & I \\
\hline 2 & No & & $>256$ & $>128$ & 4 & 2 & 8 & 16 & 1024 & 10 & & 9 & 17 & 13 & 14 & 20 & 27 & 18 & & $\mathrm{~S}$ & $\mathrm{~s}$ & $\mathrm{R}$ & $\mathrm{R}$ & $\mathrm{R}$ & $\mathrm{s}$ & $\mathrm{R}$ & $\mathrm{R}$ & $\mathrm{R}$ & $\mathrm{R}$ & $\mathrm{R}$ \\
\hline 2 & No & & $>256$ & $>128$ & 4 & 2 & 8 & 16 & 1024 & 10 & & 9 & 16 & 13 & 14 & 25 & 34 & 15 & & $\mathrm{~S}$ & $\mathrm{~S}$ & I & $\mathrm{R}$ & $\mathrm{R}$ & $\mathrm{s}$ & $\mathrm{R}$ & $\mathrm{R}$ & $\mathrm{R}$ & $\mathrm{R}$ & $\mathrm{R}$ \\
\hline 2 & No & & $>256$ & $>128$ & 4 & 2 & 8 & 16 & 1024 & 10 & & 9 & 18 & 15 & 14 & 20 & 27 & 16 & & $\mathrm{~s}$ & $\mathrm{~S}$ & $\mathrm{R}$ & $\mathrm{R}$ & $\mathrm{R}$ & $\mathrm{s}$ & $\mathrm{R}$ & $\mathrm{R}$ & $\mathrm{R}$ & $\mathrm{R}$ & $\mathrm{R}$ \\
\hline 3 & No & & $>256$ & $>128$ & 4 & 2 & 8 & 16 & 512 & 15 & & 9 & 16 & 12 & 14 & 24 & 35 & 14 & & $\mathrm{~S}$ & $S$ & $\mathrm{~S}$ & $\mathrm{R}$ & $\mathrm{s}$ & $\mathrm{s}$ & $\mathrm{s}$ & s & $\mathrm{s}$ & $\mathrm{s}$ & $\mathrm{s}$ \\
\hline 3 & No & & $>256$ & $>128$ & 4 & 2 & 8 & 16 & 256 & 15 & & 9 & 17 & 11 & 15 & 22 & 34 & 16 & & $\mathrm{~s}$ & $S$ & $\mathrm{~s}$ & $\mathrm{R}$ & $\mathrm{s}$ & $\mathrm{s}$ & $\mathrm{s}$ & s & $x$ & $\mathrm{~s}$ & $\mathrm{~s}$ \\
\hline 4 & Yes & & $>256$ & $>128$ & 32 & 2 & 8 & 16 & 128 & 10 & & 9 & 21 & 9 & 15 & 23 & 15 & 22 & & $\mathrm{~s}$ & $\mathrm{~s}$ & $\mathrm{~s}$ & $\mathrm{R}$ & I & $\mathrm{R}$ & $\mathrm{R}$ & $\mathrm{R}$ & $\mathrm{R}$ & $\mathrm{R}$ & $\mathrm{R}$ \\
\hline 5 & No & & $>256$ & $>128$ & 8 & 1 & 8 & 16 & 512 & 15 & & 9 & 19 & 13 & 15 & 25 & 37 & 13 & & $\mathrm{~s}$ & $S$ & $\mathrm{~s}$ & $\mathrm{R}$ & s & s & s & s & S & s & s \\
\hline 6 & Yes & & $>256$ & $>128$ & 8 & 1 & 8 & 16 & 1024 & 10 & & 9 & 21 & 9 & 14 & 20 & 29 & 15 & & I & I & $\mathrm{s}$ & $\mathrm{R}$ & $\mathrm{R}$ & $\mathrm{R}$ & $\mathrm{R}$ & $\mathrm{R}$ & $\mathrm{R}$ & $\mathrm{R}$ & I \\
\hline 7 & No & & $>256$ & $>128$ & 32 & 2 & 8 & 16 & 1024 & 10 & & 9 & 21 & 9 & 14 & 20 & 14 & 17 & & $\mathrm{~S}$ & $\mathrm{R}$ & $\mathrm{s}$ & $\mathrm{R}$ & $\mathrm{s}$ & $\mathrm{R}$ & $\mathrm{R}$ & $\mathrm{R}$ & $\mathrm{R}$ & $\mathrm{R}$ & I \\
\hline 8 & No & & $>256$ & $>128$ & 16 & 1 & 8 & 16 & 256 & 10 & & 9 & 14 & 9 & 13 & 18 & 40 & 18 & & $S$ & $\mathrm{R}$ & $\mathrm{s}$ & $\mathrm{R}$ & $\mathrm{R}$ & $\mathrm{R}$ & $\mathrm{R}$ & $\mathrm{R}$ & $\mathrm{R}$ & I & $\mathrm{s}$ \\
\hline 9 & No & & $>256$ & $>128$ & 4 & 2 & 8 & 16 & 512 & 15 & & 9 & 18 & 9 & 15 & 23 & 36 & 14 & & $\mathrm{~s}$ & $S$ & $\mathrm{~s}$ & $\mathrm{R}$ & $\mathrm{s}$ & $\mathrm{s}$ & $\mathrm{s}$ & $\mathrm{S}$ & $\mathrm{s}$ & $\mathrm{s}$ & $\mathrm{s}$ \\
\hline 10 & Yes & & $>256$ & $>128$ & 8 & 1 & 8 & 16 & 128 & 15 & & 9 & 18 & 9 & 11 & 15 & 11 & 17 & & $S$ & $\mathrm{~S}$ & $\mathrm{~s}$ & $\mathrm{R}$ & I & $\mathrm{R}$ & $\mathrm{R}$ & $\mathrm{R}$ & $\mathrm{R}$ & $R$ & $\mathrm{R}$ \\
\hline 11 & No & & $>256$ & $>128$ & 8 & 2 & 8 & 16 & 512 & 10 & & 9 & 23 & 14 & 15 & 23 & 44 & 16 & & $\mathrm{~s}$ & $\mathrm{~s}$ & $\mathrm{~s}$ & $\mathrm{x}$ & $\mathrm{s}$ & $\mathrm{s}$ & $\mathrm{x}$ & s & $\mathrm{s}$ & $\mathrm{s}$ & $\mathrm{s}$ \\
\hline \multirow[t]{4}{*}{12} & Yes & & $>256$ & $>128$ & 32 & 2 & 8 & 32 & 256 & 10 & & 9 & 21 & 9 & 7 & 15 & 42 & 17 & & $\mathrm{R}$ & $\mathrm{R}$ & $\mathrm{R}$ & $\mathrm{R}$ & $\mathrm{R}$ & $\mathrm{R}$ & $\mathrm{R}$ & $\mathrm{R}$ & $\mathrm{R}$ & $\mathrm{R}$ & $\mathrm{R}$ \\
\hline & & $\mu \mathrm{g} / \mathrm{ml}$ & & & & & & & & & $\mathrm{mm}$ & & & & & & & & & & & & & & & & & & & \\
\hline & & 50 & $>256$ & $>128$ & 8 & 2 & 8 & 16 & 1024 & 10 & Mean & 9 & 18.9 & 10.6 & 12.5 & 19.6 & 28.9 & 16.7 & \%susc & 90 & 65 & 80 & 0 & 30 & 40 & 22 & 25 & 21 & 30 & 35 \\
\hline & & 90 & $>256$ & $>128$ & 32 & 2 & 8 & 32 & 1024 & 15 & Range & 9 & $14-23$ & $9-15$ & $7-15$ & $15-25$ & $10-44$ & 3-22 & & & & & & & & & & & & \\
\hline
\end{tabular}

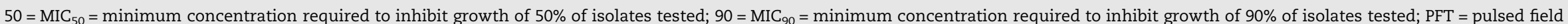

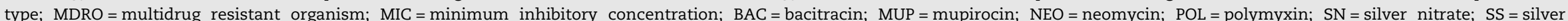

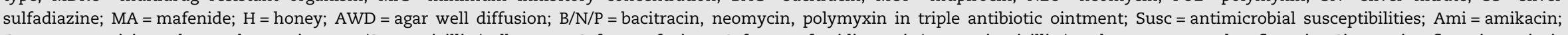
Gent = gentamicin; Tobra = tobramycin; Amp/S = ampicillin/sulbactam; Cefep = cefepime; Ceftaz = ceftazidime; Pip/tazo = pipericillin/tazobactam; Levo = levofloxacin; Cipro = ciprofloxacin; Imi = mipenem; Mero = meropenem; \%susc $=\%$ susceptible out of those isolates tested against a specific antimicrobial agent; $\mathrm{S}=$ susceptible; $\mathrm{R}=$ resistant; $\mathrm{I}=$ intermediate susceptibility; $\mathrm{X}=$ not tested. 
relatedness of ABC, MRSA, P. aeruginosa, and K. pneumoniae isolates was determined by PFGE as previously described using a CHEF-DRIII system (Bio-Rad Laboratories, Hercules, California) [27-29]. The endonuclease Apa I was used for ABC PFGE, Sma I for MRSA PFGE, Xba I for K. pneumoniae PFGE, and Spe I for P. aeruginosa PFGE. Gel images were analyzed using BioNumerics software (Applied Maths, Austin, TX). PFGE profiles were compared using the Dice coefficient and grouped into pulsed field types using established criteria [30].

\subsection{Broth microdilution assay}

Minimum inhibitory concentrations (MIC) of tested compounds were determined using custom prepared 96-well MIC panels (Trek Diagnostic, Cleveland, $\mathrm{OH}$ ), within the following concentration ranges: bacitracin, $0.12-256 \mu \mathrm{g} / \mathrm{ml}$; mupirocin, 0.06-128 $\mu \mathrm{g} / \mathrm{ml}$; neomycin, 0.5-1024 $\mu \mathrm{g} / \mathrm{ml}$; polymixin $\mathrm{B}, 0.5-$ $1024 \mu \mathrm{g} / \mathrm{ml}$; silver nitrate, 0.12-256 $\mu \mathrm{g} / \mathrm{ml}$; silver sulfadiazine, 2-4096 $\mu \mathrm{g} / \mathrm{ml}$; mafenide acetate, 16-4096 $\mu \mathrm{g} / \mathrm{ml}$; and medical grade honey, $0-50 \%$. The panels were thawed at room temperature and inoculated with a 95 pin disposable inoculator, according to the manufacturer's directions. To prepare the inoculum, fresh overnight cultures were suspended in sterile deionized water to meet a 0.5 McFarland standard. One milliliter of the cell suspension was pipetted into $29 \mathrm{ml}$ of sterile deionized water and vortexed. The $30 \mathrm{ml}$ cell suspension was poured into the inoculation tray and the 95 pin inoculator was placed into the inoculation tray with the empty pin spot aligned with the negative growth control well on the panel. The inoculators were then removed and discarded. The MIC panel was incubated at $37^{\circ} \mathrm{C}$ for $24 \mathrm{~h}$. After incubation, the panels were scored for growth. A button of $2 \mathrm{~mm}$ or larger was considered positive for growth. All isolates and drugs were tested in duplicate. If there was a greater than 2 dilution difference between each test for an individual isolate, the experiment was repeated. When reporting the data, the first run isolate that was within 2 dilutions of the other isolate was used. For each antimicrobial agent, the $\mathrm{MIC}_{50}$ and $\mathrm{MIC}_{90}$ were determined. The MIC $_{50}$ was defined as the minimum concentration required to inhibit growth of $50 \%$ of the isolates tested. Likewise, the $\mathrm{MIC}_{90}$ was defined as the minimum concentration required to inhibit growth of $90 \%$ of the isolates tested.

\subsection{Agar well diffusion}

All isolates were tested against the following commercial topical antimicrobial agents: bacitracin ointment $500 \mathrm{U} / \mathrm{g}$ (Perrigo, Allegan, MI), mafenide acetate cream $85 \mathrm{mg} / \mathrm{g}$ (UDL Laboratories Inc., Rockford, IL), $2 \%$ mupirocin ointment (ClayPark Labs Inc., Bronx, NY); 0.5\% silver nitrate solution (Teva Pharmaceutical, Sellersville, PA), 1\% silver sulfadiazine cream (Par Pharmaceutical Inc., Spring Valley, NY), and triple antibiotic ointment containing bacitracin zinc (400 bacitracin units), polymyxin B sulfate (5000 polymyxin B units), and neomycin sulfate (5 mg, $3.5 \mathrm{mg}$ neomycin base) (E. Fougera \& Co., Melville, NY), and medical grade honey (Active Manuka Honey, USA). All of the antimicrobial agents except for silver nitrate were assayed using the Nathan agar well diffusion method [22]. The silver nitrate was tested by standard disk diffusion [31]. Briefly, $9 \mathrm{~mm}$ wells were made in Mueller-
Hinton II agar plates using a sterile bore and then filled with $0.25 \mathrm{ml}$ of antimicrobial agent. All of the wells were then sealed with 2-3 drops of $1.5 \%$ agar. The plates were inoculated using the agar overlay method [32]. Using fresh overnight cultures, a cell suspension was made in normal saline to make a 0.5 McFarland standard. A melted $\left(45-50{ }^{\circ} \mathrm{C}\right) 9.0 \mathrm{ml} 1.5 \%$ agar blank was then inoculated with $1 \mu$ l of the cell suspension, mixed gently by inversion, and then poured over the MuellerHinton agar plates. Once the agar overlay had solidified, $6 \mathrm{~mm}$ paper disks (BD BBL, Franklin Lakes, NJ) containing $10 \mu \mathrm{l}$ of the silver nitrate solution were placed on the agar overlay. The plates were incubated for $24 \mathrm{~h}$ at $37^{\circ} \mathrm{C}$. Following incubation, the zones of inhibition were measured to the nearest millimeter. All agents and isolates were tested in duplicate. If there was a greater than $3 \mathrm{~mm}$ difference in zone size between the first and second test for a particular isolate, the experiment was repeated for that particular antimicrobial agent. When reporting data, the first run experiment with results within $3 \mathrm{~mm}$ of the other was reported. The average zone of inhibition size was calculated for each agent and reported as a mean and range.

\section{Results}

Twenty isolates each of ABC, P. aeruginosa, and MRSA, and 22 isolates of $K$. pneumoniae from patients in the burn center were obtained from the hospital laboratory. Most of the isolates of each species were from a unique patient though one patient had two ABC isolates included. The isolates were from blood, skin and wounds, cerebrospinal fluid, and respiratory sites. The isolates were classified into clonal type based on pulsedfield gel electrophoresis data. ABC and P. aeruginosa were categorized as MDR or not based on susceptibilities to systemic antimicrobial agents (Tables 2-5). Forty-five percent of the $P$. aeruginosa isolates and $75 \%$ of the $A B C$ isolates were categorized as MDR. All of the K. pneumoniae isolates were ESBL-producers.

For each antimicrobial agent, the $\mathrm{MIC}_{50}$ and $\mathrm{MIC}_{90}$ were determined from the broth microdilution results and the mean zones of inhibition were calculated from the agar well diffusion (Tables 2-5). For MRSA (Table 2), 18/20 isolates (90\%) had MICs of $>256 \mu \mathrm{g} / \mathrm{ml}$ to bacitracin and mafenide acetate had MICs ranging from 512 to $1024 \mu \mathrm{g} / \mathrm{ml}$, with the MIC $_{50}$ and MIC $_{90}$ both $1024 \mu \mathrm{g} / \mathrm{ml}$. Neomycin had wide range of MICs, from $<0.5$ to $>1024 \mu \mathrm{g} / \mathrm{ml}$. The topical antimicrobials containing silver, silver nitrate and silver sulfadiazine, had MICs ranging from 8 to $16 \mu \mathrm{g} / \mathrm{ml}$ with silver nitrate and from 32 to $64 \mu \mathrm{g} / \mathrm{ml}$ for silver sulfadiazine. Polymyxin B also had a moderate range of MICs, from 16 to $64 \mu \mathrm{g} / \mathrm{ml}$, with $\mathrm{MIC}_{50}$ of $16 \mu \mathrm{g} / \mathrm{ml}$ and $\mathrm{MIC}_{90}$ of $32 \mu \mathrm{g} / \mathrm{ml}$. The MICs for honey against MRSA ranged from 5 to $20 \mu \mathrm{g} / \mathrm{ml}$. Mupirocin had the lowest range of MICs for MRSA, with MIC $_{50}$ of $1 \mu \mathrm{g} / \mathrm{ml}$ and MIC $_{90}$ of $2 \mu \mathrm{g} / \mathrm{ml}$, making it the most active agent against MRSA by the broth microdilution method. Similarly, by the agar well diffusion method, mupirocin overall had very large zones of inhibition of $150 \mathrm{~mm}$ (the size of the plate) making it the topical agent with the best parameters for MRSA by both methods. Zones of inhibition for the silver-containing agents, again, were in the moderate range, with mafenide acetate and 
Table 5 - Pulsed-field type, broth microdilution, agar well diffusion, and antibiotic resistance profiles for Acinetobacter baumannii-calcoaceticus complex isolates from burn patients.

\begin{tabular}{|c|c|c|c|c|c|c|c|c|c|c|c|c|c|c|c|c|c|c|c|c|c|c|c|c|c|c|c|c|c|}
\hline \multicolumn{2}{|l|}{$\mathrm{ABC}$} & \multicolumn{9}{|c|}{ Broth microdilution } & \multicolumn{8}{|c|}{ Agar well diffusion } & \multicolumn{11}{|c|}{ Antimicrobial agents } \\
\hline PFT & MDRO & MIC & BAC & MUP & NEO & POL & SN & SS & MA & $\mathrm{H}$ & AWD & BAC & MUP & $\mathrm{B} / \mathrm{N} / \mathrm{P}$ & SN & SS & MA & $\mathrm{H}$ & Susc & Ami & Gent & Tobra & Cef & Ceft & Pip & Levo & Cip & Imi & Mero \\
\hline 1 & Yes & & $>256$ & $>128$ & 64 & $<0.5$ & 8 & 16 & 1024 & 15 & & 9 & 18 & 15 & 6 & 19 & 27 & 18 & & $\mathrm{R}$ & $\mathrm{R}$ & $\mathrm{R}$ & $\mathrm{x}$ & $\mathrm{s}$ & $\mathrm{R}$ & $\mathrm{R}$ & $\mathrm{R}$ & $\mathrm{R}$ & $\mathrm{R}$ \\
\hline 1 & Yes & & $>256$ & $>128$ & 8 & 1 & 8 & 16 & 1024 & 15 & & 9 & 16 & 9 & 10 & 13 & 22 & 20 & & $\mathrm{R}$ & $\mathrm{R}$ & $\mathrm{R}$ & $\mathrm{X}$ & I & $\mathrm{R}$ & I & $\mathrm{R}$ & $\mathrm{R}$ & $\mathrm{R}$ \\
\hline 1 & Yes & & $>256$ & $>128$ & 16 & $<0.5$ & 8 & 16 & 1024 & 15 & & 9 & 19 & 9 & 10 & 14 & 22 & 21 & & $\mathrm{R}$ & $\mathrm{R}$ & $\mathrm{R}$ & $\mathrm{x}$ & $\mathrm{s}$ & $\mathrm{R}$ & I & $\mathrm{R}$ & $\mathrm{R}$ & $\mathrm{R}$ \\
\hline 1 & Yes & & $>256$ & $>128$ & 16 & $<0.5$ & 8 & 16 & 1024 & 15 & & 9 & 16 & 9 & 10 & 14 & 23 & 19 & & $\mathrm{R}$ & $\mathrm{R}$ & $\mathrm{R}$ & $\mathrm{x}$ & $\mathrm{s}$ & $\mathrm{R}$ & I & $\mathrm{R}$ & $\mathrm{R}$ & $\mathrm{R}$ \\
\hline 1 & Yes & & $>256$ & $>128$ & 32 & 2 & 8 & 32 & 2048 & 15 & & 9 & 16 & 9 & 11 & 14 & 23 & 21 & & $\mathrm{R}$ & $\mathrm{R}$ & $\mathrm{R}$ & $\mathrm{x}$ & $\mathrm{s}$ & $\mathrm{R}$ & $\mathrm{R}$ & $\mathrm{R}$ & $\mathrm{R}$ & $\mathrm{R}$ \\
\hline 2 & Yes & & $>256$ & $>128$ & 32 & $<0.5$ & 8 & 16 & 1024 & 20 & & 9 & 20 & 9 & 9 & 16 & 28 & 18 & & $\mathrm{R}$ & $\mathrm{R}$ & $\mathrm{R}$ & $\mathrm{x}$ & $\mathrm{R}$ & $\mathrm{R}$ & $\mathrm{R}$ & $\mathrm{R}$ & $\mathrm{s}$ & $\mathrm{s}$ \\
\hline 3 & No & & $>256$ & $>128$ & 32 & 1 & 8 & 16 & 1024 & 20 & & 9 & 20 & 9 & 13 & 19 & 25 & 17 & & $\mathrm{~S}$ & $\mathrm{~S}$ & $\mathrm{~s}$ & $\mathrm{x}$ & $\mathrm{R}$ & $\mathrm{R}$ & $\mathrm{s}$ & $\mathrm{s}$ & $\mathrm{s}$ & $\mathrm{S}$ \\
\hline 4 & No & & $>256$ & $>128$ & 4 & 1 & 8 & 32 & 2048 & 10 & & 9 & 16 & 9 & 11 & 19 & 24 & 18 & & $\mathrm{~s}$ & $\mathrm{R}$ & $\mathrm{s}$ & $\mathrm{x}$ & $\mathrm{R}$ & $\mathrm{R}$ & $\mathrm{R}$ & $\mathrm{R}$ & $\mathrm{s}$ & $\mathrm{s}$ \\
\hline 5 & Yes & & $>256$ & $>128$ & 64 & 1 & 8 & 16 & 1024 & 20 & & 9 & 22 & 9 & 11 & 18 & 22 & 18 & & $\mathrm{R}$ & $\mathrm{R}$ & $\mathrm{S}$ & $\mathrm{R}$ & $\mathrm{R}$ & $\mathrm{R}$ & $\mathrm{R}$ & $\mathrm{R}$ & $\mathrm{R}$ & $\mathrm{R}$ \\
\hline 5 & Yes & & $>256$ & $>128$ & 64 & $<0.5$ & 8 & 32 & 2048 & 20 & & 9 & 22 & 9 & 12 & 19 & 23 & 17 & & $\mathrm{R}$ & $\mathrm{R}$ & I & $\mathrm{x}$ & $\mathrm{R}$ & $\mathrm{R}$ & $\mathrm{R}$ & $\mathrm{R}$ & $\mathrm{R}$ & $\mathrm{R}$ \\
\hline 5 & Yes & & $>256$ & $>128$ & 64 & $<0.5$ & 8 & 32 & 1024 & 20 & & 9 & 22 & 9 & 10 & 20 & 24 & 17 & & $\mathrm{R}$ & $\mathrm{R}$ & $\mathrm{R}$ & $\mathrm{R}$ & $\mathrm{R}$ & $\mathrm{x}$ & $\mathrm{R}$ & $\mathrm{R}$ & $\mathrm{R}$ & $\mathrm{R}$ \\
\hline 7 & Yes & & $>256$ & $>128$ & 32 & $<0.5$ & 8 & 16 & 2048 & 20 & & 9 & 21 & 9 & 12 & 21 & 30 & 22 & & $\mathrm{R}$ & $\mathrm{R}$ & I & $\mathrm{x}$ & $\mathrm{R}$ & $\mathrm{R}$ & $\mathrm{R}$ & $\mathrm{R}$ & $\mathrm{R}$ & $\mathrm{R}$ \\
\hline 7 & Yes & & $>256$ & $>128$ & 256 & 1 & 8 & 16 & 1024 & 20 & & 9 & 23 & 9 & 11 & 19 & 25 & 18 & & $\mathrm{R}$ & $\mathrm{R}$ & $\mathrm{s}$ & $\mathrm{x}$ & $\mathrm{R}$ & $\mathrm{R}$ & $\mathrm{R}$ & $\mathrm{R}$ & $\mathrm{R}$ & $\mathrm{R}$ \\
\hline 13 & No & & $>256$ & $>128$ & 1024 & $<0.5$ & 8 & 32 & 2048 & 20 & & 9 & 20 & 9 & 10 & 19 & 23 & 18 & & $\mathrm{~s}$ & $\mathrm{R}$ & $\mathrm{s}$ & $\mathrm{x}$ & $\mathrm{R}$ & $\mathrm{R}$ & $\mathrm{R}$ & $\mathrm{R}$ & $\mathrm{s}$ & $\mathrm{s}$ \\
\hline 14 & Yes & & $>256$ & $>128$ & 128 & 1 & 16 & 32 & 1024 & 20 & & 9 & 20 & 9 & 11 & 20 & 28 & 18 & & I & $\mathrm{R}$ & $\mathrm{R}$ & $\mathrm{R}$ & $\mathrm{R}$ & $\mathrm{x}$ & $\mathrm{R}$ & $\mathrm{R}$ & $\mathrm{R}$ & $\mathrm{R}$ \\
\hline 18 & Yes & & $>256$ & $>128$ & 32 & $<0.5$ & 8 & 16 & 2048 & 15 & & 9 & 22 & 9 & 9 & 15 & 34 & 21 & & $\mathrm{R}$ & $\mathrm{R}$ & $\mathrm{R}$ & $\mathrm{x}$ & $\mathrm{R}$ & $\mathrm{R}$ & $\mathrm{R}$ & $\mathrm{R}$ & $\mathrm{s}$ & $\mathrm{s}$ \\
\hline 18 & Yes & & $>256$ & $>128$ & $>1024$ & $<0.5$ & 8 & 16 & 2048 & 10 & & 9 & 16 & 9 & 10 & 15 & 32 & 20 & & $\mathrm{R}$ & $\mathrm{R}$ & $\mathrm{R}$ & $\mathrm{x}$ & $\mathrm{R}$ & $\mathrm{R}$ & $\mathrm{R}$ & $\mathrm{R}$ & $\mathrm{s}$ & $\mathrm{x}$ \\
\hline 33 & No & & $>256$ & $>128$ & 32 & 1 & 8 & 4 & 256 & 20 & & 9 & 19 & 21 & 10 & 25 & 34 & 16 & & $\mathrm{~s}$ & $\mathrm{~s}$ & $\mathrm{~s}$ & $\mathrm{x}$ & $\mathrm{s}$ & $\mathrm{R}$ & $\mathrm{s}$ & I & $\mathrm{s}$ & $\mathrm{s}$ \\
\hline 36 & No & & $>256$ & $>128$ & 2 & $<0.5$ & 8 & 16 & 512 & 20 & & 9 & 20 & 9 & 11 & 19 & 22 & 19 & & $\mathrm{~s}$ & $\mathrm{R}$ & $\mathrm{s}$ & $\mathrm{x}$ & $\mathrm{s}$ & $\mathrm{R}$ & $\mathrm{s}$ & $\mathrm{R}$ & $\mathrm{s}$ & $\mathrm{s}$ \\
\hline \multirow[t]{4}{*}{38} & Yes & & $>256$ & $>128$ & 32 & $<0.5$ & 8 & 32 & 4096 & 20 & & 9 & 20 & 9 & 12 & 19 & 24 & 20 & & $\mathrm{R}$ & $\mathrm{R}$ & $\mathrm{s}$ & $\mathrm{x}$ & $\mathrm{R}$ & $\mathrm{R}$ & $\mathrm{R}$ & $\mathrm{R}$ & $\mathrm{R}$ & $\mathrm{R}$ \\
\hline & & $\mu \mathrm{g} / \mathrm{ml}$ & & & & & & & & & $\mathrm{mm}$ & & & & & & & & & & & & & & & & & & \\
\hline & & 50 & $>256$ & $>128$ & 32 & $<0.5$ & 8 & 16 & 1024 & 20 & mean & 9 & 19.4 & 9.9 & 10.5 & 17.9 & 25.8 & 18.8 & \%susc & 25 & 10 & 40 & 0 & 30 & 0 & 15 & 5 & 40 & 37 \\
\hline & & 90 & $>256$ & $>128$ & 256 & 1 & 8 & 32 & 2048 & 20 & range & 9 & $16-23$ & $9-21$ & $6-13$ & $13-25$ & $22-34$ & $16-22$ & & & & & & & & & & & \\
\hline
\end{tabular}

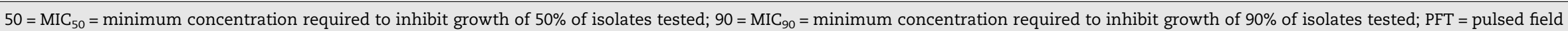

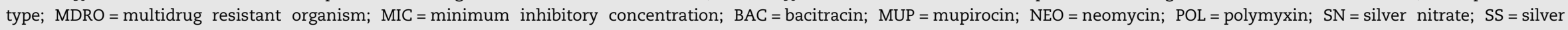
sulfadiazine; $\mathrm{MA}=$ mafenide; $\mathrm{H}=$ honey; $\mathrm{AWD}=$ agar well diffusion; $\mathrm{B} / \mathrm{N} / \mathrm{P}=$ bacitracin, neomycin, polymyxin in triple antibiotic ointment; Susc = antimicrobial susceptibilities; Ami = amikacin; Gent = gentamicin; Tobra = tobramycin; Amp/S = ampicillin/sulbactam; Cefep = cefepime; Ceftaz = ceftazidime; Pip/tazo = pipericillin/tazobactam; Levo = levofloxacin; Cipro = ciprofloxacin; Imi = $\mathrm{i}-$

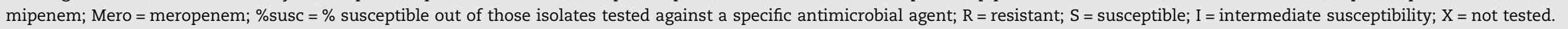


honey also falling into the moderate range by agar well diffusion. The diffusion zone for bacitracin was $9 \mathrm{~mm}$ for all isolates, meaning that the bacteria grew directly up to the well, since $9 \mathrm{~mm}$ is the size of the well. For 19/20 isolates (95\%), the triple antibiotic ointment containing bacitracin, neomycin, and polymyxin B had diffusion zones of $9 \mathrm{~mm}$. There were 7 different pulsed-field types (PFTs) among the 20 MRSA isolates, though there was generally no consistency among the types as to MICs, zones of inhibition, and antibiotic susceptibility profiles. The 2 isolates with lower bacitracin MICs were not the same PFT. One USA300 MRSA isolate had lower MICs to bacitracin, neomycin, and honey and a higher zone of inhibition to the triple antibiotic ointment, along with susceptibility to all systemic antibiotics tested. However, the other 4 USA300 clones did not show the same susceptibility profiles.

Results differed somewhat for the gram-negative organisms, K. pneumoniae (Table 3), P. aeruginosa (Table 4), and ABC (Table 5). For these organisms, bacitracin again had MICs $>256 \mu \mathrm{g} / \mathrm{ml}$, as did mafenide acetate. The $\mathrm{MIC}_{50}$ for mafenide acetate for all organisms was $1024 \mu \mathrm{g} / \mathrm{ml}$. Silver nitrate and silver sulfadiazine again had moderate MICs, as did honey. In contrast to MRSA, the MICs for mupirocin for the gram-negative organisms were all $>128 \mu \mathrm{g} / \mathrm{ml}$. For the gram-negatives, polymyxin B had low MICs, though MICs for neomycin to K. pneumoniae were even lower. Bacitracin again had zones of inhibition on agar well diffusion of $9 \mathrm{~mm}$ indicating growth right up to the well for all gramnegative isolates, as did most of the isolates against the triple antibiotic mix. The silver containing agents and honey had moderately sized zones of inhibition. Mafenide acetate had the largest average zone of inhibition against both $P$. aeruginosa and ABC (Tables 4 and 5); it also had a large zone of inhibition against K. pneumoniae however for that organism, mupirocin had the largest mean zone of inhibition (Table 3). There were no statistically significant correlations between MIC and zone of inhibition (for those agents where correlation could be performed) except for with $P$. aeruginosa and silver sulfadiazine, where the correlation was weakly negative at $-0.65(p=0.002)$ and with $\mathrm{K}$. pneumoniae and mafenide, where the correlation was also weakly negative at $-0.63(p=0.002)$. It would be expected to see a negative correlation in this case as theoretically MICs should decrease with rising zones of inhibition. Overall, the $P$. aeruginosa and ABC isolates classified as MDR using the above definition did not appear to have more resistance to the topical antimicrobial agents than their nonMDR counterparts. As with MRSA, there was not consistency between PFT and susceptibility profile. The P. aeruginosa isolates with high MICs to neomycin were of different PFTs and did not result in any lower zones of inhibition with the triple antibiotic ointment. Only $2 / 3$ of them were MDR. The same applies for ABC and neomycin, where isolates with the highest MICs to neomycin were of different PFTs, had the same zone of inhibition with the triple antibiotic ointment, and no significant difference in resistance to systemic antibiotics.

\section{Discussion}

In an era of increasing resistance to systemic antimicrobials necessitating use of second and third line and often more toxic agents, topical antimicrobial agents are an appealing choice for burn wound infections, given a theoretical decreased risk of systemic toxicities and the ability to position the antiinfective agent directly at the site of the infection, which is helpful in the setting of the avascularized tissue present in burn eschar [18]. In addition, early excision and grafting is not the standard of care worldwide and cannot always be performed even in our center due to delays in transport from austere settings to higher echelons of care. In that setting, topical agents can be very helpful as prophylaxis against burn wound infection. However, while we can easily obtain data about the susceptibility profiles of our commonly used systemic antibiotics, susceptibility information about topical agents is not readily available to help guide choice of topical therapy and furthermore, susceptibility breakpoints have not yet been standardized for these agents.

In this study we determined the susceptibility of topical antimicrobial agents against bacterial isolates of MRSA, ABC, ESBL-producing $K$. pneumoniae, and $P$. aeruginosa from burn patients using two previously described methods and compared these susceptibilities against the clonal type of the organism and susceptibility to systemic antimicrobial agents. We found that similar to previous studies, mafenide acetate is the most active agent overall against gram-negatives with mupirocin most active against MRSA. Silver had moderate efficacy as well, consistent with prior literature. Unlike other studies, however, we did not note increased resistance to topicals associated with MDR isolates vs. non-MDR isolates. Honey, which has not been evaluated using these techniques in the prior literature, had both moderate zones of inhibition and MICs against all of the isolates.

Both the agar well diffusion and broth microdilution methods have merits and flaws. Broth microdilution has been found to be more objective and reproducible than agar well diffusion. However, the agar well diffusion method requires the agents to diffuse in agar which takes into account their associated carriers, perhaps better mimicking the activity of these agents in burn eschar [22]. Neither method truly accounts for activity of the agents at the level of eschar and skin and further studies are needed to determine tissue levels.

We found that mupirocin had the best activity against MRSA, which is not surprising given prior studies on mupirocin. MICs were high and zones of inhibition were moderate against $P$. aeruginosa, which also corroborates with prior literature indicating that mupirocin is not an ideal antipseudomonal agent. Mafenide acetate was the best agent to cover all three gram-negative organisms by agar well diffusion though by MIC testing, it did not appear as effective. This has been described in prior studies. While it is concerning that mafenide acetate does not perform well in vitro, there have been multiple studies in vivo documenting its ability to diffuse through eschar so one might interpret the large zones of inhibition as more indicative of mafenide's performance in vivo $[3,5,23,33]$. It is not surprising that zones of inhibition are scant for bacitracin, as it has been shown previously to not diffuse well through agar [23]. However, the high MICs also raise concern that these isolates were resistant even without the need to diffuse and raises concern about bacitracin being successfully used in this setting. The triple antibiotic ointment containing neomycin, polymyxin $\mathrm{B}$, and bacitracin generally had low-to-moderate zones of inhibition with moderate-to- 
high MICs except in the case of K. pneumoniae. Neomycin has previously been noted to be the most active component of this triple therapy and so the fact that the neomycin has the lowest MICs against K. pneumoniae and the triple antibiotic ointment has the largest zone of inhibition with K. pneumoniae correlates well with prior reports that neomycin does not have good activity against $P$. aeruginosa. The results from honey's activity are interesting, in particular because honey is not an agent currently employed in our burn unit. By broth microdilution, honey had moderate MICs against all organisms, along with moderate zones of inhibition by agar well diffusion. Further research on the antimicrobial properties of honey to determine its spectrum and mechanism of action are needed as well as further standardization of medical grade (versus food grade) honey to ensure safety and reproducible outcomes.

As we move forward in treating burn patients with burn wound infections it will continue to be important to evaluate the appropriateness of our choices of topical antimicrobial therapy as increasing drug resistance ensues. Though our research did not show that MDR organisms had significantly different susceptibility profiles than non-MDR organisms, it was not designed to specifically show that difference since all of the S. aureus isolates were MRSA and all of the K. pneumoniae isolates were ESBL-producers. Future work could be performed to better evaluate whether susceptibility differences exist between MDR and non-MDR organisms in this setting. In addition, though we have substantial in vitro data describing the antimicrobial spectrum of activity of these agents, and we can get a sense of how they, in combination with their carriers, will diffuse in vivo by using the agar well diffuse method, at this point there is inadequate data describing how well these agents penetrate normal skin versus eschar in terms of their ability to obtain therapeutic drug levels. Further clinical studies with these agents and their carriers on skin and eschar are needed to ultimately determine standardized breakpoints so isolates can be classified as susceptible or resistant to topical agents. Bodies such as the Clinical and Laboratory Standards Institute (CLSI) should consider developing guidelines for use of topical agents.

Until we have gained further information, it seems reasonable to continue to use silver containing agents empirically for the prophylaxis of burn wound infection and mafenide acetate for the treatment of likely gram-negative burn wound infection. Mupirocin appear to be the best choice if MRSA infection is likely in a specific clinical setting. Bacitracin appears less effective using these methods while honey shows promise, although more clinical data are needed before making substantial changes to clinical practice.

\section{R E F E R E N C E S}

[1] Church D, Elsayed S, Reid O, Winston B, Lindsay R. Burn wound infections. Clin Microbiol Rev 2006;19:403-34.

[2] Gomez R, Murray CK, Hospenthal DR, Cancio LC, Renz EM, Holcomb JB, et al. Causes of mortality by autopsy findings of combat casualties and civilian patients admitted to a burn unit. J Am Coll Surg 2009;208:348-54.

[3] Robson MC. Bacterial control in the burn wound. Clin Plast Surg 1979;6:515-22.
[4] Mayhall CG. The epidemiology of burn wound infections: then and now. Clin Infect Dis 2003;37:543-50.

[5] Brown TP, Cancio LC, McManus AT, Mason Jr AD. Survival benefit conferred by topical antimicrobial preparations in burn patients: a historical perspective. J Trauma 2004;56:863-6.

[6] D'Avignon LC, Saffle JR, Chung KK, Cancio LC. Prevention and management of infections associated with burns in the combat casualty. J Trauma 2008;64:S277-86.

[7] Kwakman PH, Van den Akker JP, Guclu A, Aslami H, Binnekade JM, de Boer L, et al. Medical-grade honey kills antibiotic-resistant bacteria in vitro and eradicates skin colonization. Clin Infect Dis 2008;46:1677-82.

[8] Neely AN, Gardner J, Durkee P, Warden GD, Greenhalgh DG, Gallagher JJ, et al. Are topical antimicrobials effective against bacteria that are highly resistant to systemic antibiotics? J Burn Care Res 2009;30:19-29.

[9] Winkelman W, Gratton D. Topical antibacterials. Clin Dermatol 1989;7:156-62.

[10] Klasen HJ. Historical review of the use of silver in the treatment of burns. I. Early uses. Burns 2000;26:117-30.

[11] Moncrief JA. The development of topical therapy. J Trauma 1971;11:906-10.

[12] Bergamini TM, Lamont PM, Cheadle WG, Polk Jr HC. Combined topical and systemic antibiotic prophylaxis in experimental wound infection. Am J Surg 1984;147:753-6.

[13] Moncrief JA, Lindberg RB, Switzer WE, Pruitt Jr BA. The use of a topical sulfonamide in the control of burn wound sepsis. J Trauma 1966;6:407-19.

[14] Moncrief JA, Lindberg RB, Switzer WE, Pruitt Jr BA. Use of topical antibacterial therapy in the treatment of the burn wound. Arch Surg 1966;92:558-65.

[15] Allen BD, Whitson TC, Henjyoji EY. Treatment of 1,963 burned patients at 106th general hospital, Yokohama, Japan. J Trauma 1970;10:386-92.

[16] Fox Jr CL. Silver sulfadiazine-a new topical therapy for Pseudomonas in burns. Therapy of Pseudomonas infection in burns. Arch Surg 1968;96:184-8.

[17] Lansdown AB. Silver. I. Its antibacterial properties and mechanism of action. J Wound Care 2002;11:125-30.

[18] Davis SC, Pisanni F, Montero RB. Effects of commonly used topical antimicrobial agents on Acinetobacter baumannii: an in vitro study. Mil Med 2008;173:74-8.

[19] Sutherland R, Boon RJ, Griffin KE, Masters PJ, Slocombe B, White AR. Antibacterial activity of mupirocin (pseudomonic acid), a new antibiotic for topical use. Antimicrob Agents Chemother 1985;27:495-8.

[20] Schuenck RP, Dadalti P, Silva MG, Fonseca LS, Santos KR. Oxacillin- and mupirocin-resistant Staphylococcus aureus: in vitro activity of silver sulphadiazine and cerium nitrate in hospital strains. J Chemother 2004;16:453-8.

[21] Fuller FW. The side effects of silver sulfadiazine. J Burn Care Res 2009;30:464-70.

[22] Nathan P, Law EJ, Murphy DF, MacMillan BG. A laboratory method for selection of topical antimicrobial agents to treat infected burn wounds. Burns 1978;4:177-87.

[23] Rodgers GL, Mortensen JE, Fisher MC, Long SS. In vitro susceptibility testing of topical antimicrobial agents used in pediatric burn patients: comparison of two methods. J Burn Care Rehabil 1997;18:406-10.

[24] Thomson PD, Taddonio TE, Tait MJ, Prasad JK. Susceptibility of Pseudomonas and Staphylococcus wound isolates to topical antimicrobial agents: a 10-year review and clinical evaluation. Burns 1989;15:190-2.

[25] http://www.bd.com/ds/productCenter/IS-Phoenix.asp [accessed June 25, 2009].

[26] Souli M, Galani I, Giamarellou H. Emergence of extensively drug-resistant and pandrug-resistant Gram-negative bacilli in Europe. Euro Surveill 2008;13. pii:19045. 
[27] Akers KS, Mende K, Yun HC, Hospenthal DR, Beckius ML, $\mathrm{Yu} \mathrm{X}$, et al. Tetracycline susceptibility testing and resistance genes in isolates of Acinetobacter baumanniiAcinetobacter calcoaceticus complex from a U.S. military hospital. Antimicrob Agents Chemother 2009;53:2693-5.

[28] Murray CK, Holmes RL, Ellis MW, Mende K, Wolf SE, McDougal LK, et al. Twenty-five year epidemiology of invasive methicillin-resistant Staphylococcus aureus (MRSA) isolates recovered at a burn center. Burns 2009;35:1112-7.

[29] Procedure for PFGE of Gram negative rods by FDA methodVersion 1. 10.30.2007.

[30] Tenover FC, Arbeit RD, Goering RV, Mickelsen PA, Murray $\mathrm{BE}$, Persing $\mathrm{DH}$, et al. Interpreting chromosomal DNA restriction patterns produced by pulsed-field gel electrophoresis: criteria for bacterial strain typing. J Clin Microbiol 1995;33:2233-9.

[31] Performance standards for antimicrobial disk susceptibility tests, 9th ed., Wayne, PA: Clinical and Laboratory Standards Institute; 2006.

[32] Acar J. Antibiotics in laboratory medicine. Baltimore, MD: Williams \& Wilkins; 1980.

[33] Moncrief JA. Topical therapy for control of bacteria in the burn wound. World J Surg 1978;2:151-65.

[34] Lipsky BA, Hoey C. Topical antimicrobial therapy for treating chronic wounds. Clin Infect Dis 2009;49:1541-9.

[35] Subrahmanyam M. Topical application of honey in treatment of burns. Br J Surg 1991;78:497-8.

[36] Cutting KF. Honey and contemporary wound care: an overview. Ostomy Wound Manage 2007;53:49-54.

[37] Cooper RA, Halas E, Molan PC. The efficacy of honey in inhibiting strains of Pseudomonas aeruginosa from infected burns. J Burn Care Rehabil 2002;23:366-70.

[38] Maeda Y, Loughrey A, Earle JA, Millar BC, Rao JR, Kearns A, et al. Antibacterial activity of honey against communityassociated methicillin-resistant Staphylococcus aureus (CAMRSA). Complement Ther Clin Pract 2008;14:77-82.

[39] Cooper ML, Boyce ST, Hansbrough JF, Foreman TJ, Frank DH. Cytotoxicity to cultured human keratinocytes of topical antimicrobial agents. J Surg Res 1990;48:190-5.

[40] Lowbury EJ, Lilly HA, Cason JS, Jackson DM, Bull JP, Davies $\mathrm{JW}$, et al. Alternative forms of local treatment for burns. Lancet 1971;2:1105-11.

[41] Harrison HN, Bales HW, Jacoby F. The absorption into burned skin of Sulfamylon acetate from 5 percent aqueous solution. J Trauma 1972;12:994-8.

[42] Harrison HN, Shuck JM, Caldwell E. Studies of the pain produced by mafenide acetate preparations in burns. Arch Surg 1975;110:1446.

[43] White MG, Asch MJ. Acid-base effects of topical mafenide acetate in the burned patient. N Engl J Med 1971;284:1281-6.

[44] Pirnay JP, De Vos D, Cochez C, Bilocq F, Pirson J, Struelens $\mathrm{M}$, et al. Molecular epidemiology of Pseudomonas aeruginosa colonization in a burn unit: persistence of a multidrugresistant clone and a silver sulfadiazine-resistant clone. J Clin Microbiol 2003;41:1192-202.

[45] Murphy RC, Kucan JO, Robson MC, Heggers JP. The effect of $5 \%$ mafenide acetate solution on bacterial control in infected rat burns. J Trauma 1983;23:878-81.
[46] Pappa KA. The clinical development of mupirocin. J Am Acad Dermatol 1990;22:873-9.

[47] Strock LL, Lee MM, Rutan RL, Desai MH, Robson MC, Herndon DN, et al. Topical Bactroban (mupirocin): efficacy in treating burn wounds infected with methicillin-resistant staphylococci. J Burn Care Rehabil 1990;11:454-9.

[48] Rode H, Hanslo D, de Wet PM, Millar AJ, Cywes S. Efficacy of mupirocin in methicillin-resistant Staphylococcus aureus burn wound infection. Antimicrob Agents Chemother 1989;33:1358-61.

[49] Acikel C, Oncul O, Ulkur E, Bayram I, Celikoz B, Cavuslu S. Comparison of silver sulfadiazine $1 \%$, mupirocin $2 \%$, and fusidic acid $2 \%$ for topical antibacterial effect in methicillinresistant staphylococci-infected, full-skin thickness rat burn wounds. J Burn Care Rehabil 2003;24:37-41.

[50] Leyden JJ. Mupirocin: a new topical antibiotic. J Am Acad Dermatol 1990;22:879-83.

[51] Macdonald RH, Beck M. Neomycin: a review with particular reference to dermatological usage. Clin Exp Dermatol 1983;8:249-58.

[52] Holder IA. Wet disc testing of mafenide hydrochloride, chlorhexidine gluconate, and triple antibiotic solution against bacteria isolated from burn wounds. J Burn Care Rehabil 1990;11:301-4.

[53] Klasen HJ. A historical review of the use of silver in the treatment of burns. II. Renewed interest for silver. Burns 2000;26:131-8.

[54] Moyer CA, Brentano L, Gravens DL, Margraf HW, Monafo Jr WW. Treatment of large human burns with 0.5 per cent silver nitrate solution. Arch Surg 1965;90:812-67.

[55] Cason JS, Jackson DM, Lowbury EJ, Ricketts CR. Antiseptic and aseptic prophylaxis for burns: use of silver nitrate and of isolators. Br Med J 1966;2:1288-94.

[56] Stanford W, Rappole BW, Fox Jr CL. Clinical experience with silver sulfadiazine, a new topical agent for control of Pseudomonas infections in burns. J Trauma 1969;9:377-88.

[57] Wright JB, Lam K, Hansen D, Burrell RE. Efficacy of topical silver against fungal burn wound pathogens. Am J Infect Control 1999;27:344-50.

[58] Lansdown AB, Williams A. Bacterial resistance to silver in wound care and medical devices. J Wound Care 2007;16:15-9.

[59] George N, Faoagali J, Muller M. Silvazine (silver sulfadiazine and chlorhexidine) activity against 200 clinical isolates. Burns 1997;23:493-5.

[60] Castellano JJ, Shafii SM, Ko F, Donate G, Wright TE, Mannari RJ, et al. Comparative evaluation of silver-containing antimicrobial dressings and drugs. Int Wound J 2007;4:11422.

[61] Choban PS, Marshall WJ. Leukopenia secondary to silver sulfadiazine: frequency, characteristics and clinical consequences. Am Surg 1987;53:515-7.

[62] Herruzo-Cabrera R, Garcia-Torres V, Rey-Calero J, VizcainoAlcaide MJ. Evaluation of the penetration strength, bactericidal efficacy and spectrum of action of several antimicrobial creams against isolated microorganisms in a burn centre. Burns 1992;18:39-44.

[63] Lansdown AB. Silver. 2. Toxicity in mammals and how its products aid wound repair. J Wound Care 2002;11:173-7. 